\title{
Dynamic Mechanical Behavior and Numerical Simulation of Frozen Soil under Impact Loading
}

\author{
Dan Zhang, ${ }^{1}$ Zhiwu Zhu, ${ }^{1,2}$ and Zhijie Liu' \\ ${ }^{1}$ School of Mechanics and Engineering, Southwest Jiaotong University, Chengdu 610031, China \\ ${ }^{2}$ State Key Laboratory of Frozen Soil Engineering, CAREERI, CAS, Lanzhou 730000, China \\ Correspondence should be addressed to Zhiwu Zhu; zZw4455@163.com
}

Received 31 March 2016; Revised 21 June 2016; Accepted 21 June 2016

Academic Editor: Onome E. Scott-Emuakpor

Copyright (C) 2016 Dan Zhang et al. This is an open access article distributed under the Creative Commons Attribution License, which permits unrestricted use, distribution, and reproduction in any medium, provided the original work is properly cited.

\begin{abstract}
Split Hopkinson pressure bars (SHBP) were used to perform impact experiments on frozen soil under various impact velocities and temperatures to analyze the effect of these parameters on the mechanical behavior of the soil. Based on the Holmquist-JohnsonCook constitutive model, the dynamic mechanical properties under impact loading were analyzed. The SHPB experiments of frozen soil were also simulated using the finite element analysis software LS-DYNA, and the simulation results were similar to the experimental results. The temperature effect, strain rate effect, and the destruction process of the frozen soil as well as the propagation process of stress waves in the incident bar, transmission bar, and frozen soil specimen were investigated. This work provides a good theoretical basis and technical support for frozen soil engineering applications.
\end{abstract}

\section{Introduction}

Frozen soil, a porous complex material, consists of mineral grains, water, ice inclusions, and gas inclusions (moisture and air); the essential difference between frozen soil and melted soil is the presence of ice. Frozen soil is widely distributed on the Earth's surface; a series of major construction projects will be performed in permafrost regions, and strong dynamic loadings will affect the structures of frozen soil. In addition, the artificial freezing method, one of the main technical techniques used in underground engineering, overcomes the limitations of the timbering range and depth and can effectively prevent the deformation of adjacent water and mining. The cutting process of frozen soil in the artificial method is essentially the processing of frozen soil under dynamic loading. Therefore, understanding the dynamic mechanical behavior of frozen soil is of great importance.

The split Hopkinson pressure bar (SHPB) method has played a significant role in the dynamic testing of materials. Chen et al. [1] studied the dynamic brittle and frozen brittle behavior of frozen soil and observed oscillation and convergence of the strain-stress curves. Zhang et al. [2] established a phenomenological model that used thermal sensitivity to describe the dynamic behavior of confined frozen soil. Ma et al. [3,4] studied the dynamic behavior of artificial frozen soil, which showed a dependence on both the temperature and strain rate. When the freezing temperature and impact pressure are fixed, the dynamic mechanical characteristics of artificial frozen soil under a uniaxial loading state and confined pressure state exhibit significant differences; the maximum stress under the confined pressure state is higher than that under the uniaxial loading state, which indicates obvious stress-strengthening characteristics. Liu et al. [5] evaluated the dynamic stress-strain curves and dynamic parameters of frozen clay at various low temperatures, water contents, and strain rates. Based on systematic impact loading experiments of frozen soil, Ma et al. [6] analyzed the characteristics of dynamic stress-strain curves, and a strain convergence phenomenon was observed; the necessity of this phenomenon in SHPB experiments was investigated. At Sandia National Laboratory $[7,8]$ in the USA, SHPB tests were performed on artificial frozen soils modeled on Alaskan examples under negative lateral confinement or nearly uniaxial strain conditions. Recently, additional SHPB tests were performed on undisturbed frozen soil from Alaska, and an attempt was made to describe its constitutive 


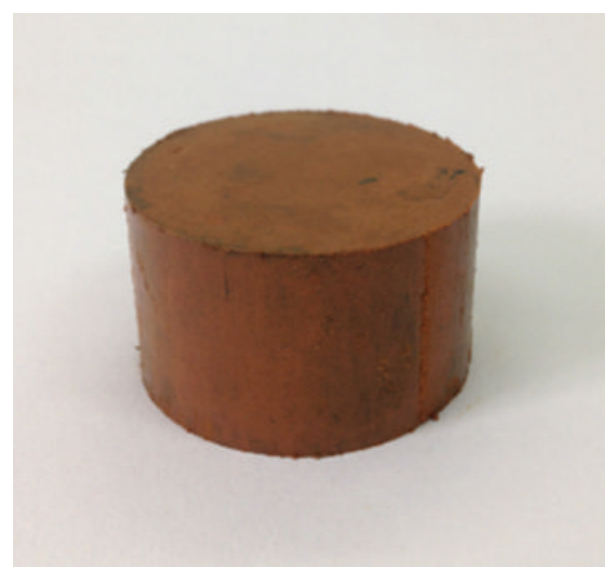

Figure 1: A frozen soil specimen before testing.

behavior using a cap plasticity model. However, because of the nonuniformity of the frozen soil in the SHPB tests and waveform dispersion effect, the SHPB device data were difficult to measure, and the experimental accuracy must be further improved. In addition, the entire process only took a few hundred microseconds and was applied to the frozen soil sample for only a few microseconds. It was thus difficult to observe the material failure process and describe the internal stress evolution law. Because of the complexity of the internal structure of frozen soil, the development of a dynamic theory is challenging.

The numerical simulation technique has recently undergone rapid development. Through numerical simulation, the stress and strain of a unit sample can be directly determined, and the destruction process of a sample can be directly observed. In addition, the effects of interfacial friction and parallelism tolerance can be avoided. Therefore, numerical simulation can also improve test accuracy. Wu et al. [9] numerically simulated SHPB tests for concrete using the Holmquist-Johnson-Cook (HJC) constitutive model. A comparison of the stress-strain curve obtained from the SHPB test with the reconstructed curve from the numerical simulation revealed similar mechanical behavior. The failure process of rock subjected to combined static and dynamic loading in SHPB tests was numerically simulated by Zhu et al. [10], and the strength increase factor under combined static and dynamic loading could be predicted. The test process of ceramics in SHPB tests was numerically simulated by Anderson et al. [11], and the dynamic condition and loss efficacy of the ceramics were studied. Chakraborty [12] used finite element software to simulate SHPB tests on rocks and achieved good correlation with experimental results. However, numerical simulation of SHPB experiments on frozen soil has not yet been reported.

Based on the existing research, in this work, the SHPB method was used to investigate the dynamic behavior of artificial frozen soil. The tests were conducted at temperatures of $-5^{\circ} \mathrm{C},-15^{\circ} \mathrm{C}$, and $-25^{\circ} \mathrm{C}$ and strain rates of $500 / \mathrm{s}, 750 / \mathrm{s}$, and $950 / \mathrm{s}$. Using the finite element software LS-DYNA, the effects of the temperature and loading strain rate on the dynamic mechanical properties of frozen soil were investigated, and
TABLE 1: Particle size distribution.

\begin{tabular}{lccccc}
\hline Size $/ \mathrm{mm}$ & $<0.1$ & $0.1 \sim 0.25$ & $0.25 \sim 0.5$ & $0.5 \sim 2$ & $>2$ \\
\hline Proportion $/ \%$ & 32 & 16 & 25 & 19 & 8 \\
\hline
\end{tabular}

the dynamic failure mode of frozen soil under impact loading was discussed.

\section{Experimental Studies}

2.1. Frozen Soil Samples and Experimental Conditions. Based on one-dimensional conditions, an assumption of homogeneity, and the size of the experimental equipment, the dimensions of all the specimens for the tests were $\phi 30 \mathrm{~mm} \times$ $18 \mathrm{~mm}$. The experimental material is the artificial frozen sand. Firstly, the sand was crushed down by a wooden hammer. Then, the large soil particles would be sifted out by a sieve with a mesh size of $2 \mathrm{~mm}$. The remaining soil was put in an oven at $110^{\circ} \mathrm{C}$ for $12 \mathrm{~h}$ and dehydrated. The soil was then placed in a sealed vessel and cooled to room temperature. The particle size of the soil was listed in Table 1.

After that, the water was mixed with the dehydrated soil to satisfy the required water content of $30 \%$, and then the mixture is stored in a closed container for $24 \mathrm{~h}$. The specimens were made from the mixture by molds and smeared Vaseline on its surface in order to keep the water content of specimens unchanged. Finally, the well-made specimens were placed in a freezer at the prescribed temperatures (i.e., $-5,-15$, and $-25^{\circ} \mathrm{C}$, resp.) for $24 \mathrm{~h}$ (see Figure 1).

2.2. Experimental Equipment. Dynamic testing of the frozen soil specimens was performed using an SHPB setup (Figure 2). An SHPB is a device used to test the dynamic mechanical behavior of materials under impact loading.

The SHPB setup used in this study consisted of a striker, an incident bar, a transmission bar, and an acquisition system. The material parameters of the striker and bars and the length of the striker are important experimental parameters. The striker is made of the $35 \mathrm{CrMnSi}$ steel whose Young's modulus is $191 \mathrm{GPa}$ and density is $8000 \mathrm{~kg} / \mathrm{m}^{3}$, and the length 


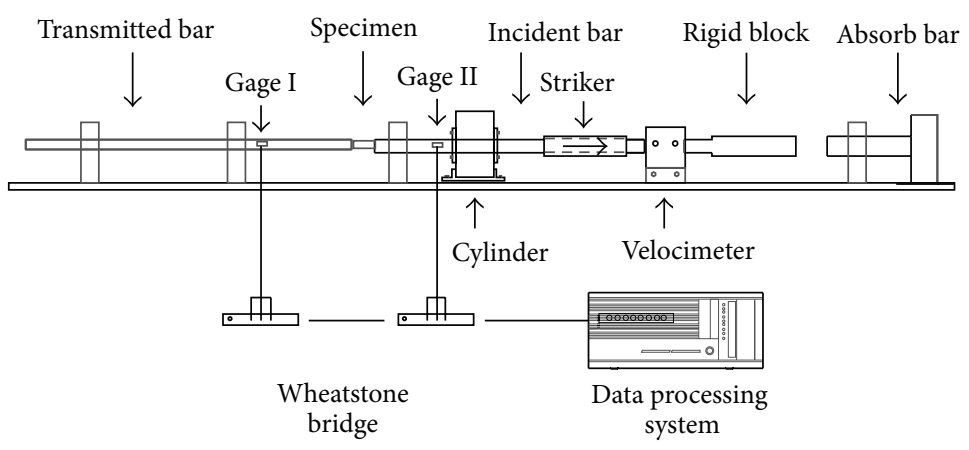

FIGURE 2: Sketch of SHPB and its testing system.

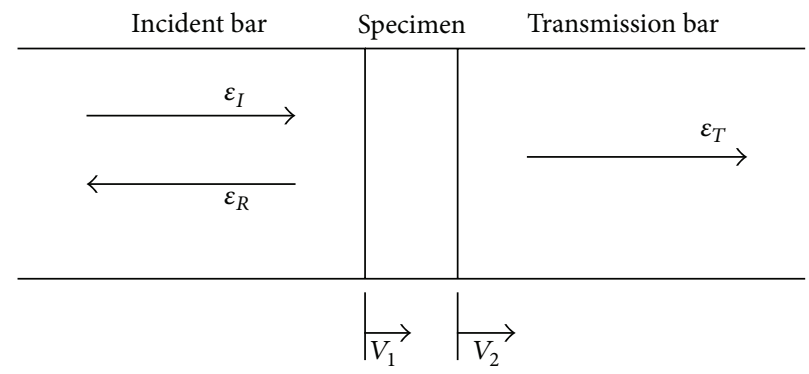

FIgURE 3: Testing section of SHPB.

of the striker is $200 \mathrm{~mm}$, the incident and transmission bars are made of the 7075-T6 aluminum whose modulus is $71 \mathrm{GPa}$ and density is $2100 \mathrm{~kg} / \mathrm{m}^{3}$, and the diameters of them are $30 \mathrm{~mm}$.

The incident and transmission bars are instrumented with strain gauges to capture the elastic stress waves generated by the striker bar. Frozen soil specimens are placed between the incident and transmission bars. The striker is launched by compressed air. An elastic compression stress wave (incident wave) is generated by the impact of the striker bar striking the incident bar. The incident wave is transmitted through the specimen as a transmitted wave and is partially reflected at the interface between the specimen and the incident bar. Both the incident and reflected waves are recorded by the strain gauge on the incident bar, and the transmitted wave is recorded by the strain gauge on the transmission bar.

Assume that the stress waves propagate in both the incident and transmission bars without dispersion; that is, the pulses recorded at the strain gage locations represent those at the bar ends in contact with the specimen; one-dimensional stress wave theory relates the particle velocities at both ends of specimen to the three measured strain pulses (Figure 3):

$$
\begin{aligned}
& v_{1}=C_{B}\left(\varepsilon_{I}-\varepsilon_{R}\right), \\
& v_{2}=C_{B} \varepsilon_{T},
\end{aligned}
$$

where $C_{B}$ is the elastic bar wave speed of the bar material and $I, R$, and $T$ represent the incident and reflected and transmitted pulses, respectively. The average engineering strain rate and strain in the specimen are

$$
\begin{aligned}
& \varepsilon=\frac{v_{1}-v_{2}}{L_{s}}=\frac{C_{B}}{L_{s}}\left(\varepsilon_{I}-\varepsilon_{R}-\varepsilon_{T}\right), \\
& \varepsilon=\int_{0}^{t} \varepsilon d t=\frac{C_{B}}{L_{s}} \int_{0}^{t}\left(\varepsilon_{I}-\varepsilon_{R}-\varepsilon_{T}\right) d t,
\end{aligned}
$$

where $L_{s}$ is the initial length of the specimen. The stresses at both ends of the specimen are calculated with the following elastic relations:

$$
\begin{aligned}
& \sigma_{1}=\frac{A_{B}}{A_{S}} \cdot E_{B}\left(\varepsilon_{I}+\varepsilon_{R}\right), \\
& \sigma_{2}=\frac{A_{B}}{A_{S}} \cdot E_{B} \cdot \varepsilon_{T},
\end{aligned}
$$

where $A_{B}$ and $A_{S}$ are the cross-sectional areas of the bars and the specimen, respectively, and $E_{B}$ is Young's modulus of the bar material.

As mentioned earlier, the specimen is assumed to be stress equilibrated in a SHPB experiment. This assumption must be satisfied in dynamic characterization of material properties. Consequently, the specimen deforms nearly uniformly such that the specimen response averaged over its volume is a good representative of the point-wise valid material behavior. The stress equilibration is expressed as

$$
\sigma_{1}=\sigma_{2} .
$$

Or from (3) and (4)

$$
\varepsilon_{I}+\varepsilon_{R}=\varepsilon_{T} .
$$



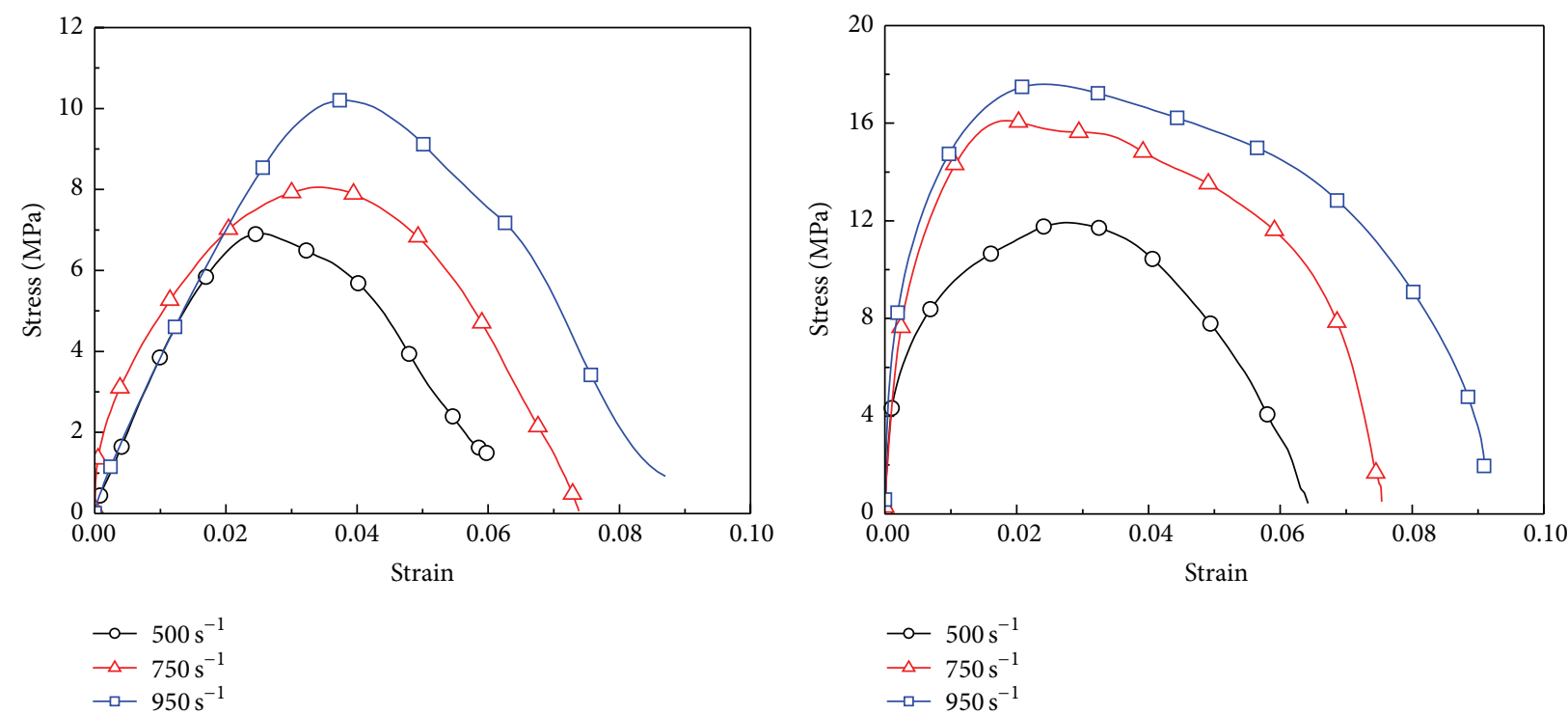

(a) $-5^{\circ} \mathrm{C}$

(b) $-15^{\circ} \mathrm{C}$

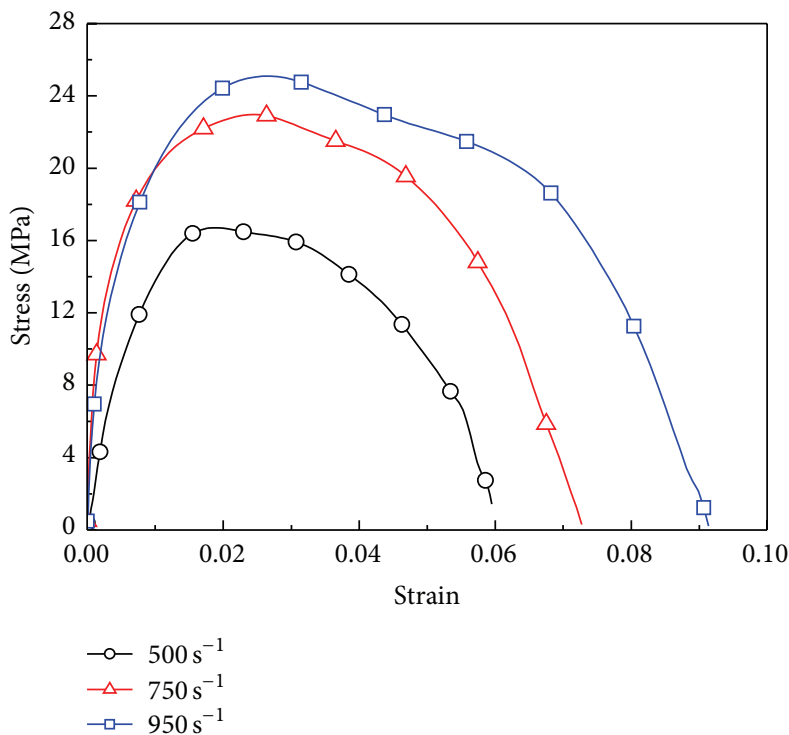

(c) $-25^{\circ} \mathrm{C}$

FIGURE 4: Stress-strain curves of frozen soil under various strain rates.

Equations (2) and (4) can thus be simplified as the follows:

$$
\begin{aligned}
\varepsilon & =-2 \frac{C_{B}}{L_{s}} \varepsilon_{R}, \\
\varepsilon & =-2 \frac{C_{B}}{L_{s}} \int_{0}^{t} \varepsilon_{R} d t, \\
\sigma & =\frac{A_{B}}{A_{S}} E_{B} \varepsilon_{T} .
\end{aligned}
$$

Therefore, once the incident, reflected, and transmitted signals are measured, the stress-strain data for the material under investigation can be obtained.
2.3. Analysis of Experimental Results. The SHPB tests were conducted on the frozen soil at three different temperatures $\left(-5^{\circ} \mathrm{C},-15^{\circ} \mathrm{C}\right.$, and $\left.-25^{\circ} \mathrm{C}\right)$ and three strain rates $(500 / \mathrm{s}, 750 / \mathrm{s}$, and 950/s). The stress-strain curves obtained after processing using the two-wave method are presented in Figure 4. The peak stress and final strain increase with increasing loading strain rates.

To more clearly illustrate the relationship between the peak stress and strain rate, the peak stress-strain rate curves for the three experimental temperatures are plotted in Figure 5.

Figure 5 illustrates that the frozen soil exhibits an obvious strain rate effect. For a fixed temperature, the peak stress increases for higher strain rates. In addition, the strain rate 


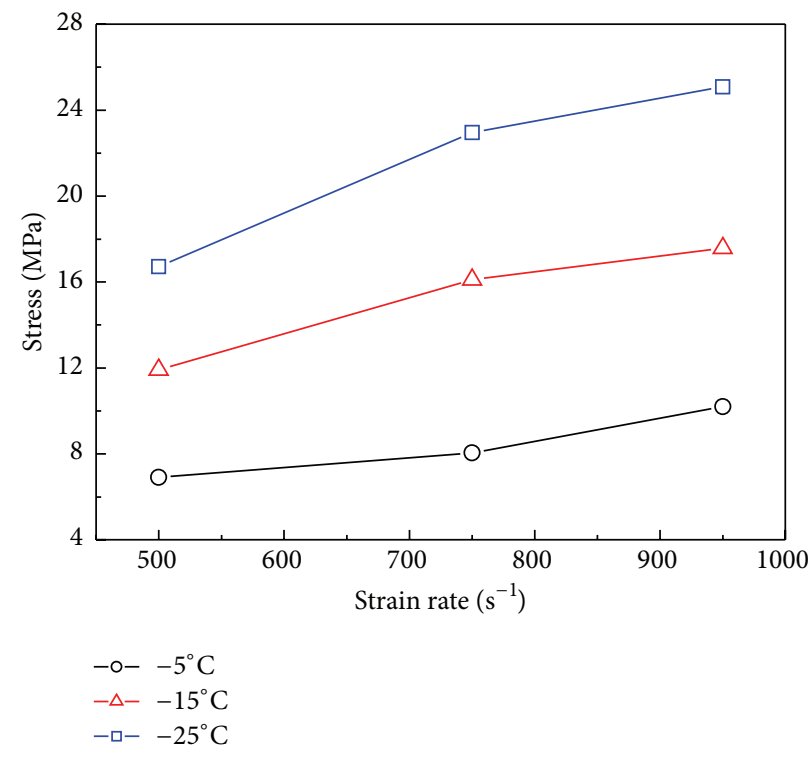

FIGURE 5: Peak stress-strain rate curves for various temperatures.

effect is more pronounced at lower temperature because ice crystals play a leading role during the entire crush resistance process. At a lower temperature, the amount of ice is greater in frozen soil; the proportion of the antipressure ability in the entire sample is thus greater, and the strain rate effect becomes more apparent.

The dynamic stress-strain curves of frozen soil for a fixed impact loading strain rate at various temperatures are plotted in Figure 6. The peak stress increases with decreasing temperature.

To more clearly illustrate the relationship between the peak stress and temperature, the peak stress-temperature curves at three different strain rates are plotted in Figure 7.

Figure 7 demonstrates the obvious temperature effect for the frozen soil. The peak stress increases upon increasing the temperature for a given strain rate. In addition, the temperature effect is more prominent at higher strain rate.

After the impact loading experiments, debris from the fractured frozen soil samples was collected. Photographs of the fractured frozen soil samples after impact loading at $-15^{\circ} \mathrm{C}$ are shown in Figure 8. It is apparent that the damage to the frozen soil was more severe at higher impact loading strain rates.

\section{Numerical Simulation Studies}

The LS-DYNA program can solve geometric nonlinearity (large displacement, large rotation, and large strain), material nonlinearity (dynamic models for more than 140 types of material), and contact nonlinearity (more than 50) problems. This program is suitable for the numerical simulation of SHPB experiments. Based on the strain rate effect and temperature effect of the frozen soil and its final destruction form, the HJC model [13] was selected to simulate the SHPB impact dynamic experiments of the frozen soil.
3.1. HJC Material Constitutive Model. The characteristics of the HJC constitutive model [13] reflect the dynamic response of brittle materials such as frozen soil:

$$
\sigma^{*}=\left[A(1-D)+B p^{* N}\right]\left(1+C \ln \dot{\varepsilon}^{*}\right),
$$

where $A$ and $B$ are the normalized intensities; $N$ and $C$ are the pressure-hardening exponent and strain rate coefficient, respectively; $\sigma^{*}=\left(\sigma / f_{c}^{\prime}\right)$ is the ratio of the real equivalent strength and quasi-static uniaxial compressive strength, which is the normalized equivalent stress; $p^{*}=\left(p / f_{c}^{\prime}\right)$ is the normalized hydrostatic force; $\dot{\varepsilon}^{*}$ is the nondimensional strain rate, a ratio of the true strain rate and reference strain rate $\dot{\varepsilon}_{0}$; and $D$ is the damage factor and is determined by the accumulation of plastic strain, which includes two parts of the equivalent plastic and plastic volumetric strain:

$$
D=\sum \frac{\Delta \varepsilon_{p}+\Delta \mu_{p}}{\varepsilon_{p}^{f}+\mu_{p}^{f}} .
$$

Here, $\Delta \varepsilon_{p}$ and $\Delta \mu_{p}$ are the equivalent plastic strain increment and plastic volumetric strain increment, respectively, and $\varepsilon_{p}^{f}$ and $\mu_{p}^{f}$ are the equivalent plastic strain and plastic volumetric strain, respectively, when frozen soil is broken under ordinary pressure.

$p$ is the actual hydrostatic pressure and can be determined by the state equation of the curve [13] shown in Figure 9.

The first stage represents the elastic compression region (OA section). Here, $p=K \mu$, where $K$ is the bulk modulus.

The second stage represents the compaction deformation region ( $A B$ section). The internal pores of the frozen soil are gradually crushed, and plastic volumetric damage will be produced. Here, $p=K^{\prime} \mu$, where $K^{\prime}=\left(p_{1}-p_{c}\right) /\left(\mu_{1}-\mu_{c}\right)$.

The third stage represents the region after the solid deformation section ( $B C$ section). The internal part of the frozen soil consists entirely of crushed close-grained material. 


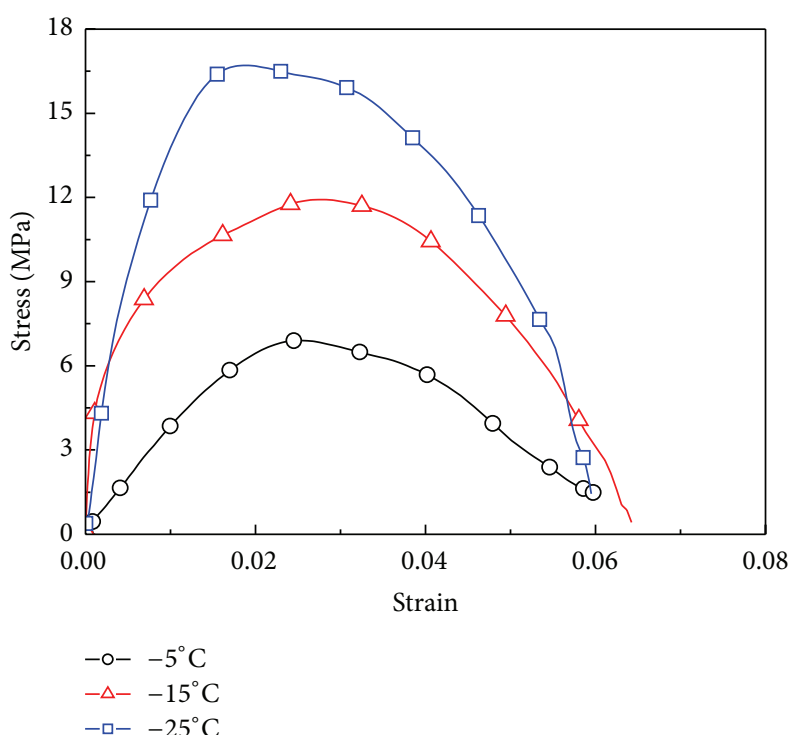

(a) $500 / \mathrm{s}$

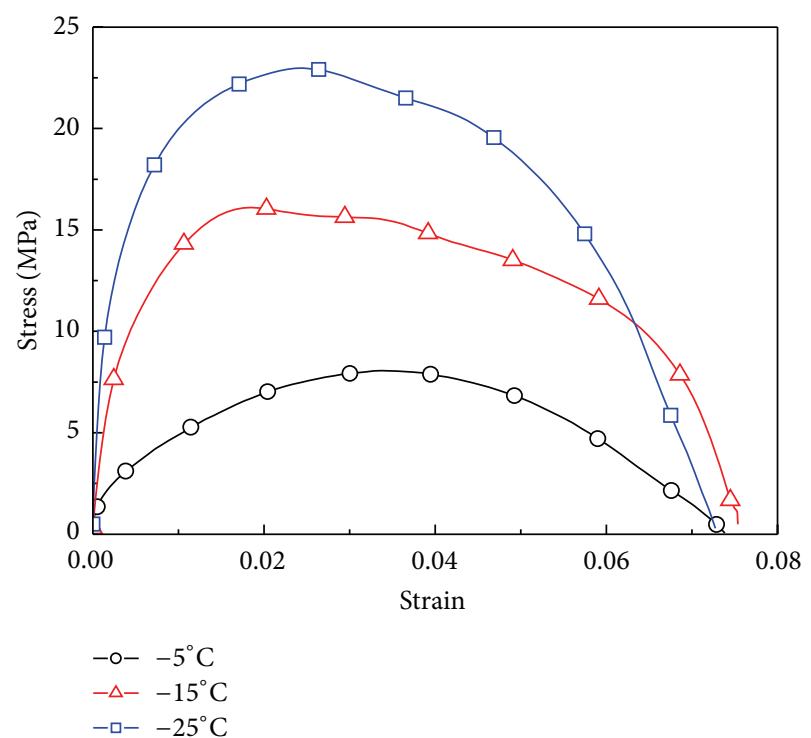

(b) $750 / \mathrm{s}$

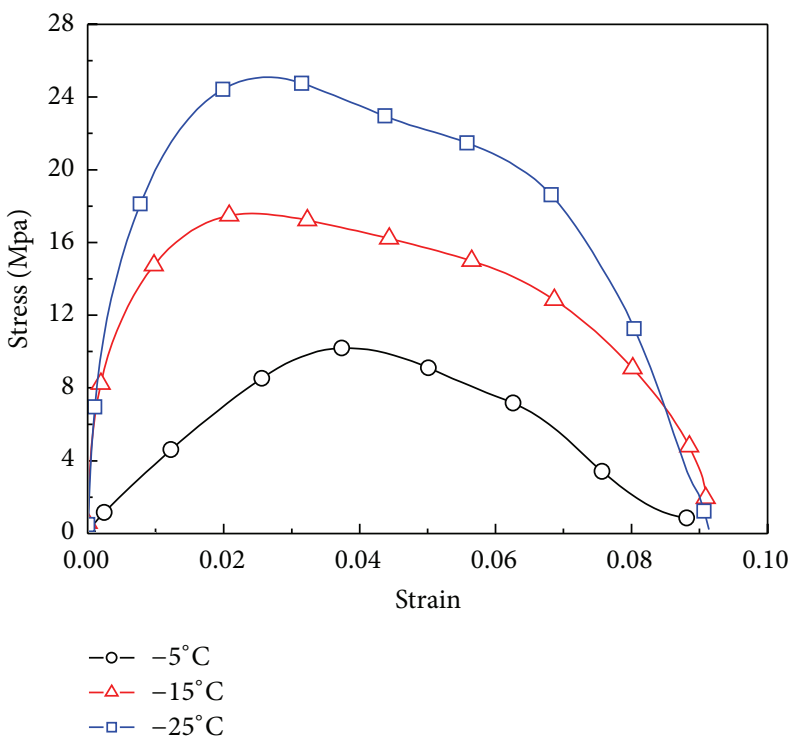

(c) $950 / \mathrm{s}$

FIGURE 6: Stress-strain curves of frozen soil under various temperatures.

Here, $p=K_{1} \mu+K_{2} \mu^{2}+K_{3} \mu^{3}$, where $K_{1}, K_{2}$, and $K_{3}$ are material constants.

The failure in the HJC model is mainly compression failure. For the tensile damage model of a brittle material, such as frozen soil, volume strain failure criteria must be appended; a failure strain of 0.005 was used.

3.2. Finite Element Model. The finite element model consisted of four parts: the bullet, incident bar, transmission bars, and sample. For comparison with the experimental results, a cylinder model with a diameter of $30 \mathrm{~mm}$ and height of $18 \mathrm{~mm}$ was used for the frozen soil. The mapping mesh method was used, which is suitable for wave propagation and dynamic contact calculation. The size of the mesh opening of the member bars was $4 \mathrm{~mm}$. Considering the calculated amount and accuracy and the size of the mesh opening of the frozen soil sample, the main part of the study was $1 \mathrm{~mm}$. Both member bars and the sample used SOLID164. Automated single face contact was used, and the friction between devices was ignored.

3.3. Selection of Material Parameters. The member bars used the linear elastic model, similar to the experimental material. The material parameters are listed in Table 2.

The study simulated frozen soil samples using the HJC model. The serial number of the HJC model was 111 in the LS-DYNA software program and consisted of 21 parameters in total. The basic material parameters were the density $R_{0}$, shear modulus $G$, static compressive strength $f_{c}$, and tensile strength $T$. The intensity parameters were $A, B, C, N$, and 


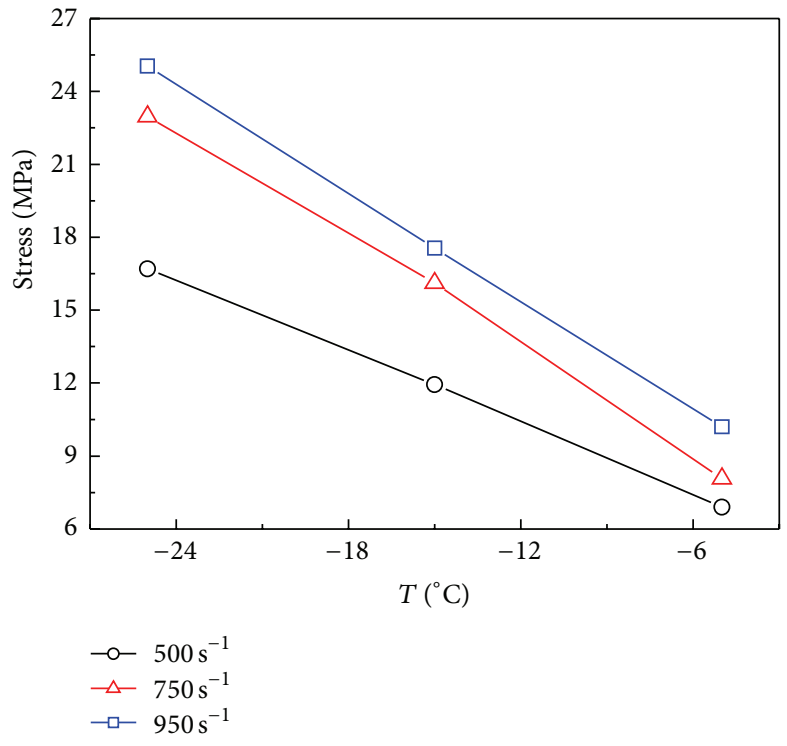

FiguRE 7: Peak stress-temperature curves under various strain rates.

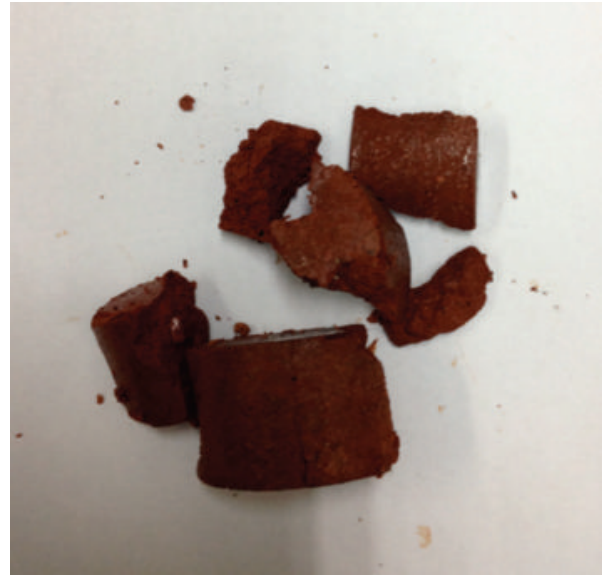

(a) $500 / \mathrm{s}$

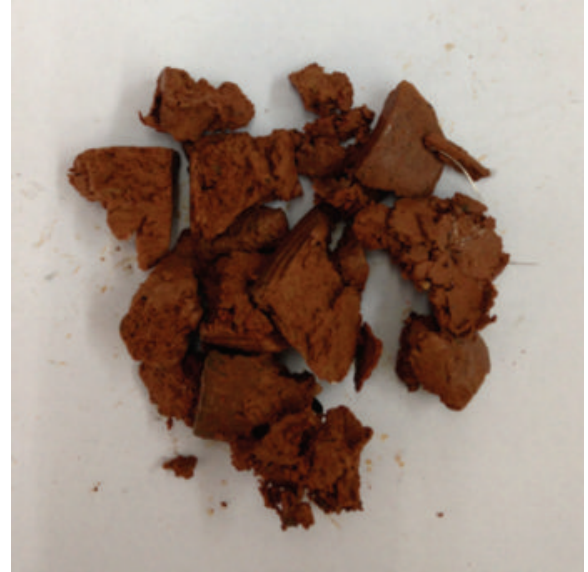

(b) $750 / \mathrm{s}$

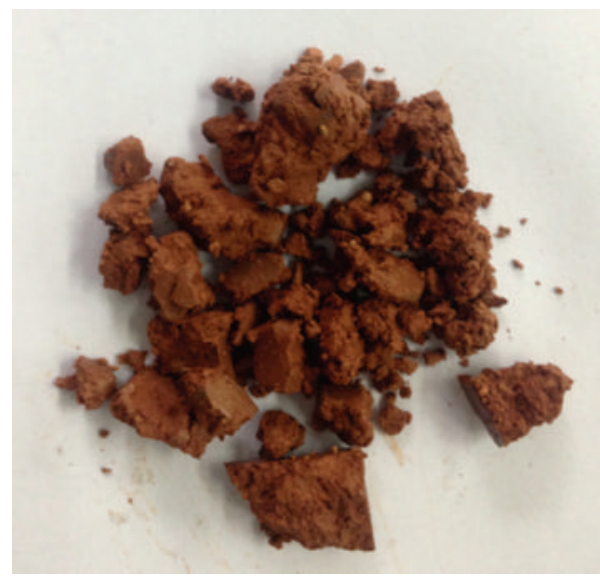

(c) $950 / \mathrm{s}$

FIGURE 8: Photographs of the fractured frozen soil samples after impact loading at various strain rates. 


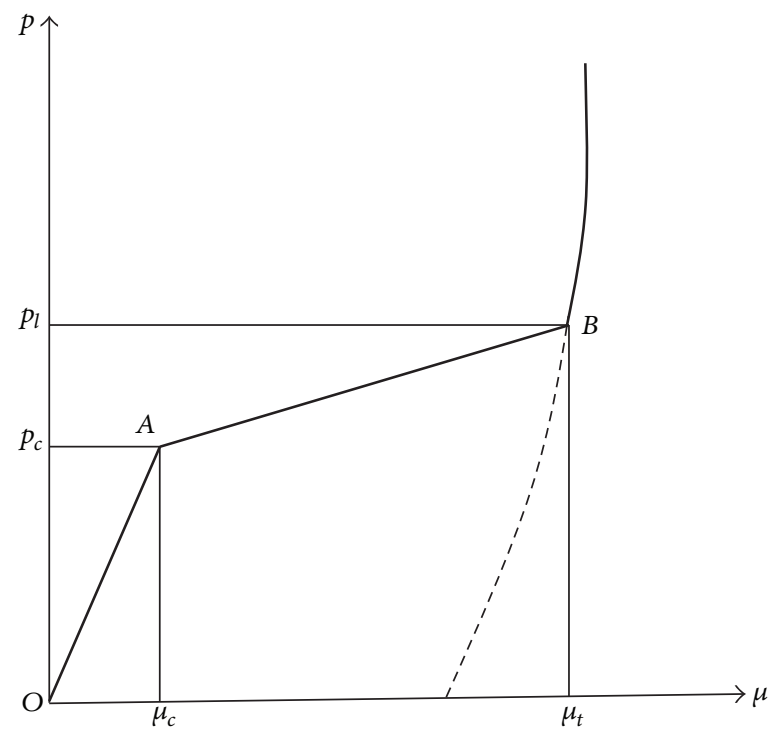

Figure 9: Hydrostatic pressure-volumetric strain curve.

TABLE 2: Linear elastic material parameters of bars.

\begin{tabular}{lccc}
\hline Device & $\mathrm{RO} / \mathrm{kg} / \mathrm{m}^{3}$ & $E / \mathrm{Pa}$ & $\mathrm{PR}$ \\
\hline Bullet & $8.00 e 3$ & $1.95 e 11$ & 0.30 \\
Incident/transmission bars & $2.10 e 3$ & $7.00 e 10$ & 0.30 \\
\hline
\end{tabular}

TABLE 3: Initial material parameters of HJC constitutive model.

\begin{tabular}{lcccccc}
\hline$\rho_{0} / \mathrm{kg} / \mathrm{m}^{3}$ & $G / \mathrm{Pa}$ & $f_{c}^{\prime} / \mathrm{Pa}$ & $A$ & $B$ & $C$ & $N$ \\
\hline $2.4 e 3$ & $14.86 e 9$ & $48 e 6$ & 0.79 & 1.60 & 0.007 & 0.61 \\
\hline$S_{\max }$ & $D_{1}$ & $D_{2}$ & $\varepsilon_{f \min }$ & $T / \mathrm{Pa}$ & $p_{c} / \mathrm{Pa}$ & $\mu_{c}$ \\
\hline 7.0 & 0.04 & 1.0 & 0.01 & $4 e 6$ & $16.0 e 6$ & 0.001 \\
\hline$p_{1} / \mathrm{Pa}$ & $\mu_{1}$ & $k_{1} / \mathrm{Pa}$ & $k_{2} / \mathrm{Pa}$ & $k_{3} / \mathrm{Pa}$ & $\dot{\varepsilon}_{0}$ & $f_{s}$ \\
\hline $0.81 e 9$ & 0.1 & $85 e 9$ & $-171 e 9$ & $208 e 9$ & $1 e-6$ & 0.004 \\
\hline
\end{tabular}

SFMAX. The damage parameters were $D_{1}, D_{2}$, and $\varepsilon_{f \min }$. The pressure parameters were $P_{c}, \mu_{c}, P_{l}, \mu_{l}, K_{1}, K_{2}$, and $K_{3}$. The reference strain rate was $\dot{\varepsilon}_{0}$, and the failure type was $f_{s}$.

In the experiments, the temperature of the frozen soil was variable. $G$ of the frozen soil is the most sensitive to temperature of the four basic parameters. The remaining three basic parameters remain basically invariant with temperature change. In this numerical simulation, $G$ changed with changing temperature. The density of frozen soil is $2100 \mathrm{~kg} / \mathrm{m}^{3}$. According to the available experimental data [14-16], $f_{c}$ is $9.0 \mathrm{MPa}, T$ is $0.3 \mathrm{MPa}$, and $G$ is in the range of 500 to $2500 \mathrm{MPa}$.

All the initial parameters of the HJC model, which are listed in Table 3, were obtained from the literature [13].

The initial parameters were used as the standard parameter set, and the sensitivity of each parameter was analyzed. When one parameter was analyzed, the other parameters were fixed. The parameter was considered a sensitive parameter if a small change in the parameter led to a large change in the result. Based on repeated numerical simulations, $A$,
$B, C$, and $N$ were determined to be sensitive parameters of the HJC model for frozen soil. In addition, it was necessary to determine the effects of the sensitive parameters on the constitutive law to provide a theoretical basis and reference guide for data fitting. In this study, the stress formula is as follows:

$$
\sigma=\frac{A_{B}}{A_{S}} E_{B} \varepsilon_{T}
$$

where $A_{B}$ and $A_{S}$ are the same; thus, the trend of the stress curve is the same as that of the transmission wave strain. To reduce the number of calculations, only the trend of the transmission wave was determined.

3.3.1. Normalized Parameters $A$ and $B . R_{0}, G, f_{c}$, and $T$ were replaced with the material parameter values of frozen soil. The remainder of the parameters were fixed, and the value of $A$ was changed. The change in the transmitted wave is plotted in Figure 10.

Figure 10 demonstrates that the peak stress increases when the parameter $A$ increases. In addition, the waveform exhibits a slight difference in that the rising period becomes steep, and the declining period becomes more gradual. This result occurs because $A$ is the cohesion strength; therefore, a greater value of $A$ results in a greater peak stress. In addition, $A$ is directly proportional to the damage, and $(1-D)$ is always positive. Hence, the stress value increases with increasing $A$.

The value of the parameter $B$ was changed separately to analyze its effect on the transmitted wave. The change of the transmitted wave is shown in Figure 11.

Figure 11 demonstrates that the peak stress increases with increasing $B$. Its elastic stage is completely overlapped, and it begins to change at the yield point. The ascent stage becomes steeper with an increase in $B$. The final declining stage almost coincides for all the values of $B$. $B$ only affects the value of the peak stress and does not control the wave shape 


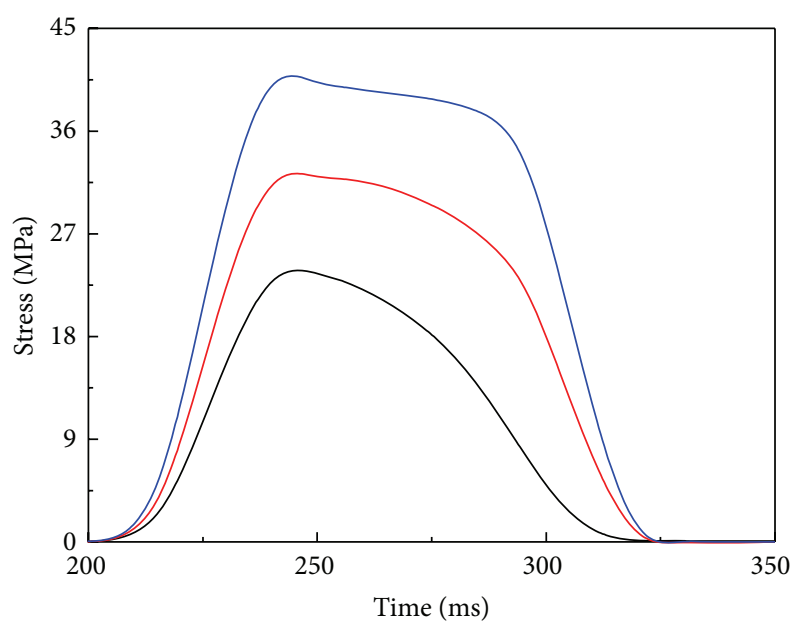

$\begin{aligned} A & =0.40 \\ A & =0.79 \\ A & =1.20\end{aligned}$

FIGURE 10: Transmitted waves for various values of $A$.

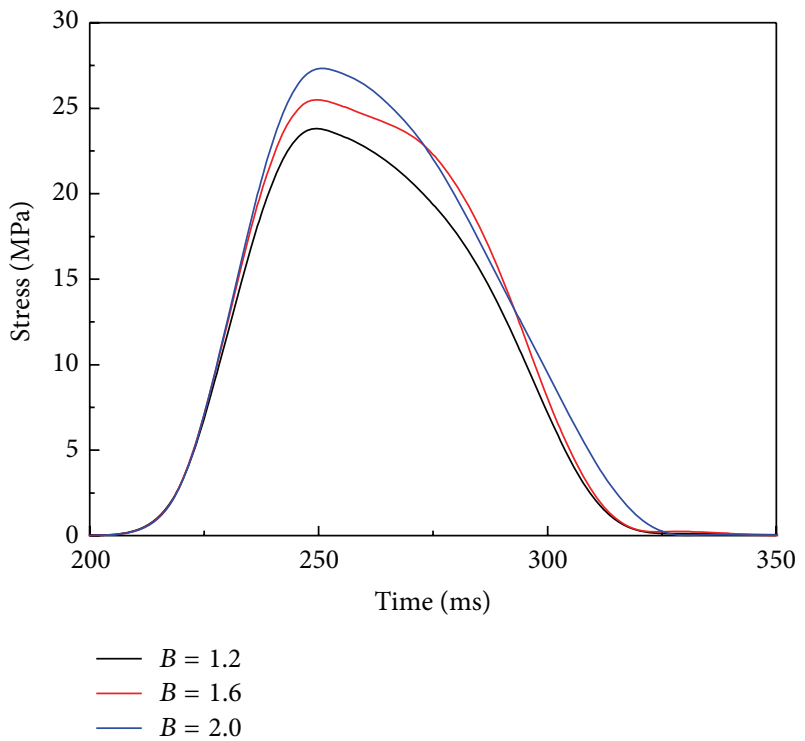

Figure 11: Transmitted waves for various values of $B$.

because $B$ is the standard strain-hardening coefficient, which is directly proportional to the pressure term in the yield surface equation.

3.3.2. Pressure-Hardening Exponent $N$. The change in the transmitted wave resulting from changing the value of $N$ is illustrated in Figure 12.

Figure 12 demonstrates that the elastic stages are primarily coincident. In the plastic stage, with increasing $N$, the rising slope is gradually reduced, and the peak stress gradually decreases. In addition, the waveform width increases with increasing $N$.

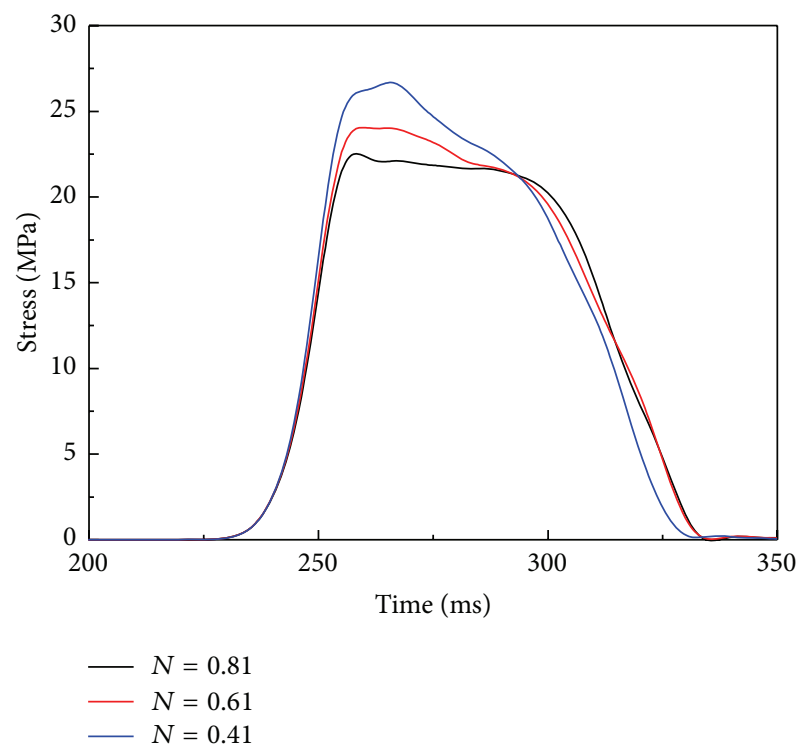

FIGURE 12: Transmitted waves for various values of $N$.

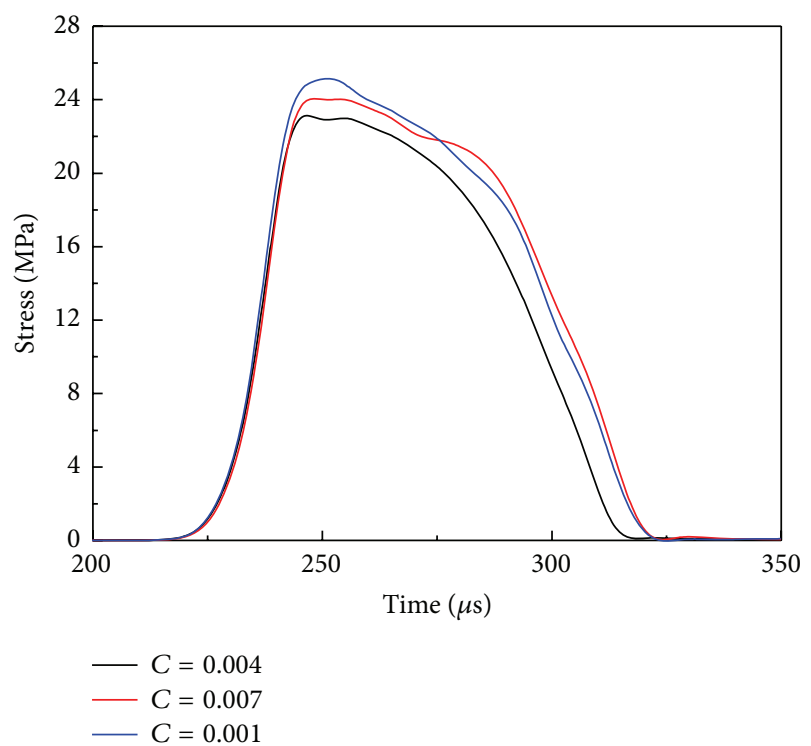

Figure 13: Transmitted waves for various values of $C$.

3.3.3. Strain Rate Coefficient $C$. The change in the transmitted wave for various values of the parameter $C$ is shown in Figure 13.

The elastic stages are observed to be almost coincident, and the slope of the yielding stage is primarily the same. Only the peak stress increases upon increasing $C$; the wave shape is not affected.

Through sensitivity analysis of the HJC parameters, the effects of the parameters on the final waveform curve were determined. $A$ and $B$ affect the value of peak stress, $N$ affects the value of the peak stress and pulse width, and $C$ affects the effect of strain rate. According to the effect of these parameters and the experimental results, $A=1.2, B=0.5$, $C=0.012$, and $N=1.0$. The frozen soil parameters of the HJC model are listed in Table 4. 


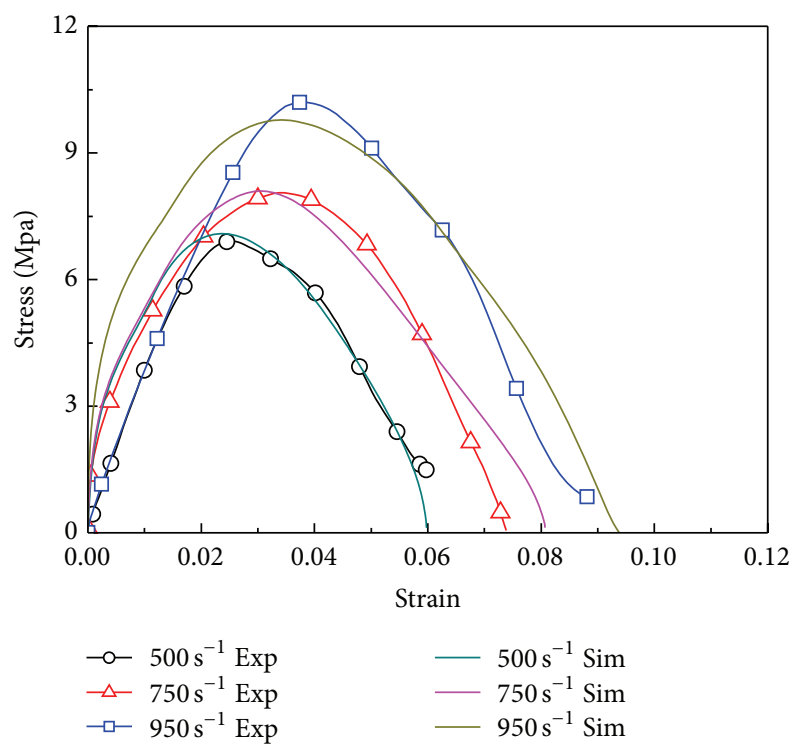

(a) $-5^{\circ} \mathrm{C}$

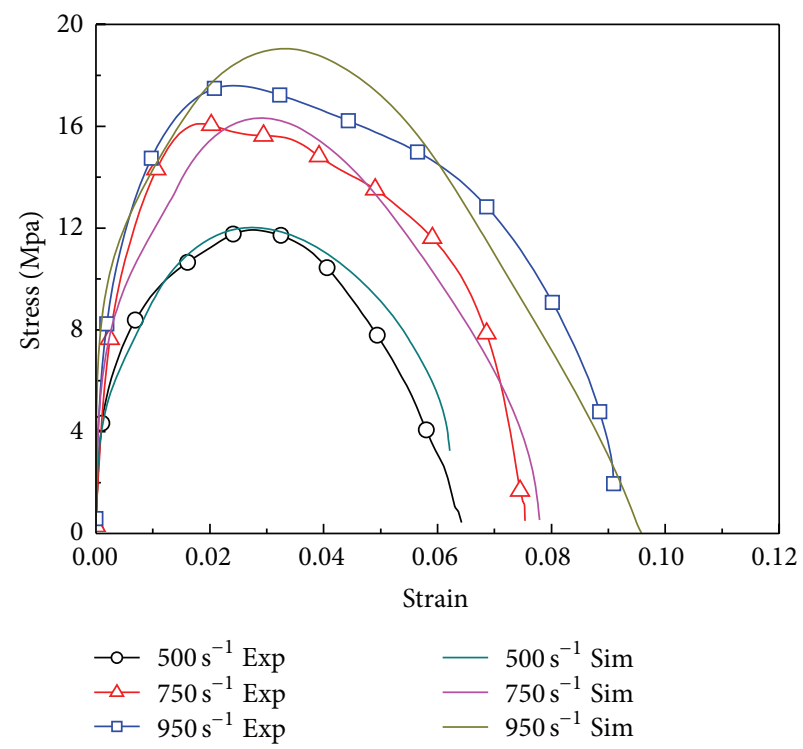

(b) $-15^{\circ} \mathrm{C}$

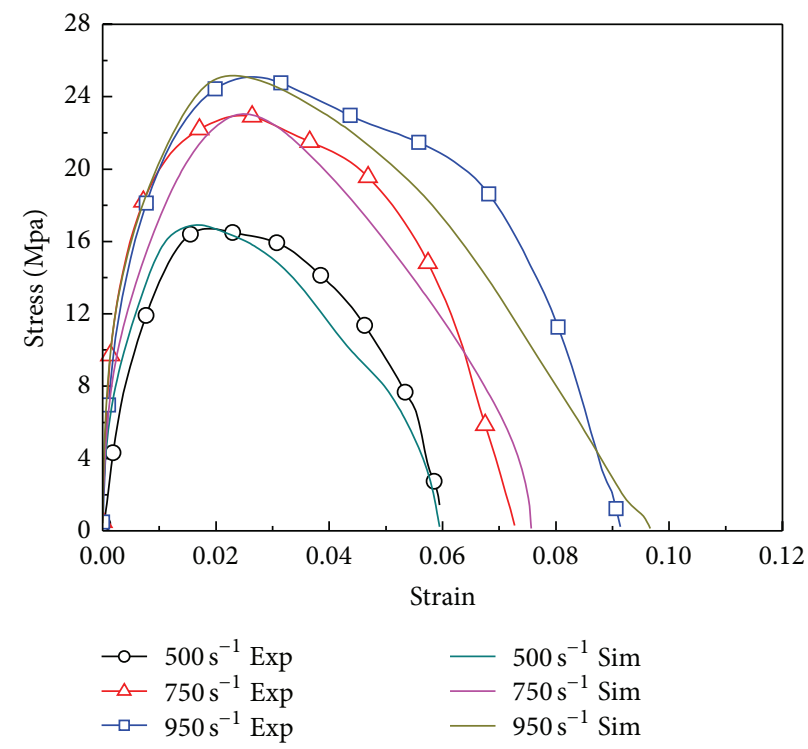

(c) $-25^{\circ} \mathrm{C}$

FIGURE 14: Comparison of experimental curves with numerical simulation curves under various strain rates.

TABLE 4: Modified material parameters of HJC constitutive model.

\begin{tabular}{lcccccc}
\hline$\rho_{0} / \mathrm{kg} / \mathrm{m}^{3}$ & $G / \mathrm{Pa}$ & $f_{c}^{\prime} / \mathrm{Pa}$ & $A$ & $B$ & $C$ & $N$ \\
\hline $2.1 e 3$ & $2 e 9$ & $9 e 6$ & 1.2 & 0.5 & 0.012 & 1.0 \\
\hline$S_{\max }$ & $D_{1}$ & $D_{2}$ & $\varepsilon_{f \min }$ & $T / \mathrm{Pa}$ & $p_{c} / \mathrm{Pa}$ & $\mu_{c}$ \\
\hline 7.0 & 0.04 & 1.0 & 0.01 & $3 e 5$ & $16.0 e 6$ & 0.001 \\
\hline$p_{1} / \mathrm{Pa}$ & $\mu_{1}$ & $k_{1} / \mathrm{Pa}$ & $k_{2} / \mathrm{Pa}$ & $k_{3} / \mathrm{Pa}$ & $\dot{\varepsilon}_{0}$ & $f_{s}$ \\
\hline $0.81 e 9$ & 0.1 & $85 e 9$ & $-171 e 9$ & $208 e 9$ & $1 e-6$ & 0.004 \\
\hline
\end{tabular}

Among these parameters, $G$ is a factor of critical influence for frozen soil as it increases sharply with decreasing temperature. Three temperatures were used in the frozen soil experiments in this paper. According to the existing experimental data [16], $G$ is 500,1500 , and $2500 \mathrm{MPa}$ when the temperature is $-5^{\circ} \mathrm{C},-15^{\circ} \mathrm{C}$, and $-25^{\circ} \mathrm{C}$, respectively.

\section{Results and Analyses}

4.1. Strain Rate Effect and Temperature Effect. The incident reflected waves and transmitted wave were processed using the two-wave method, and then, the stress-strain curves were reconstructed for comparison with the SHPB experimental curves. The first group of experiments was performed at a given temperature, and the experimental strain rates were altered by changing the impact speed; the numerical simulation curves are compared with the experimental curves in Figure 14. 


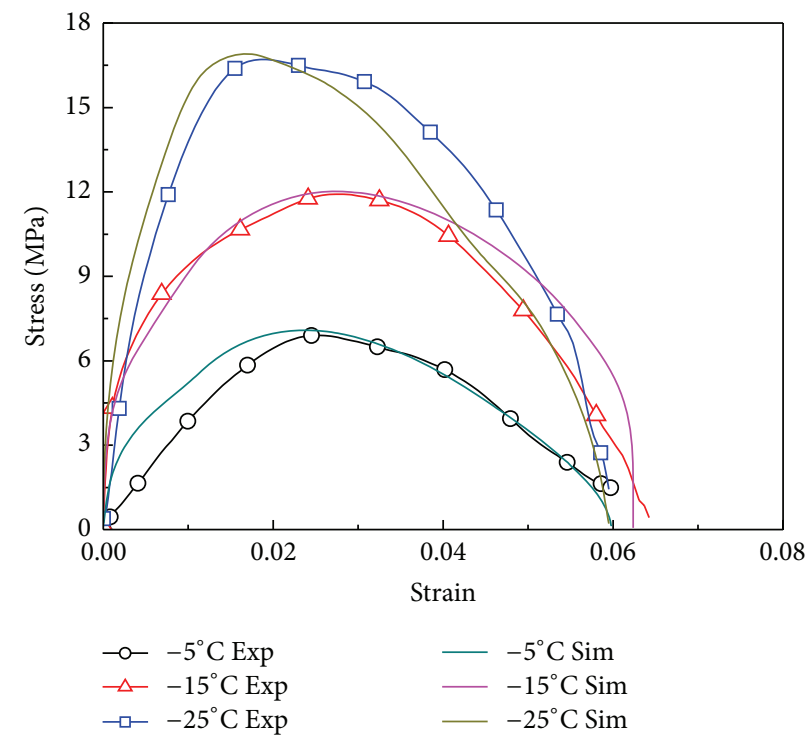

(a) $500 / \mathrm{s}$

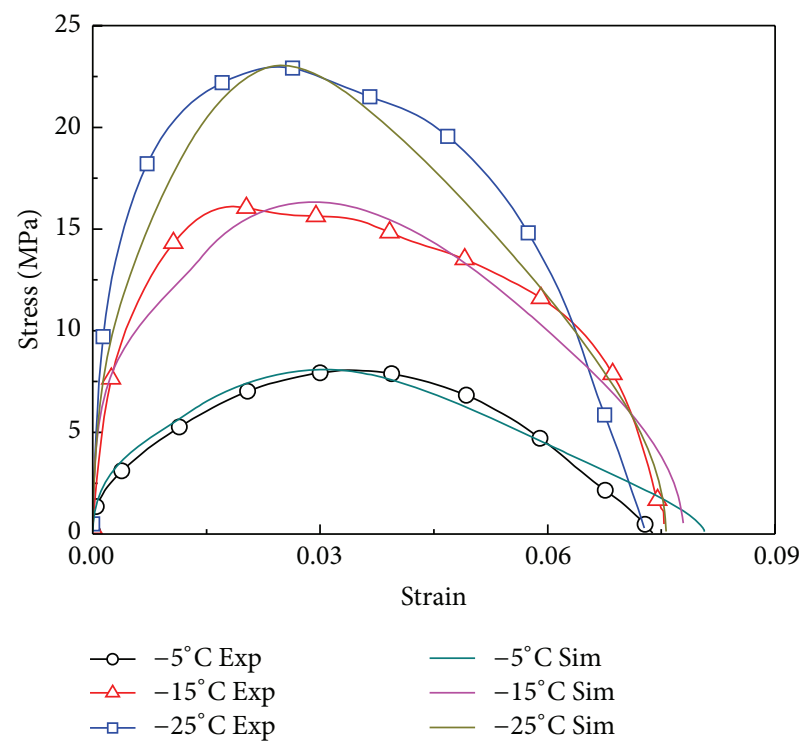

(b) $750 / \mathrm{s}$

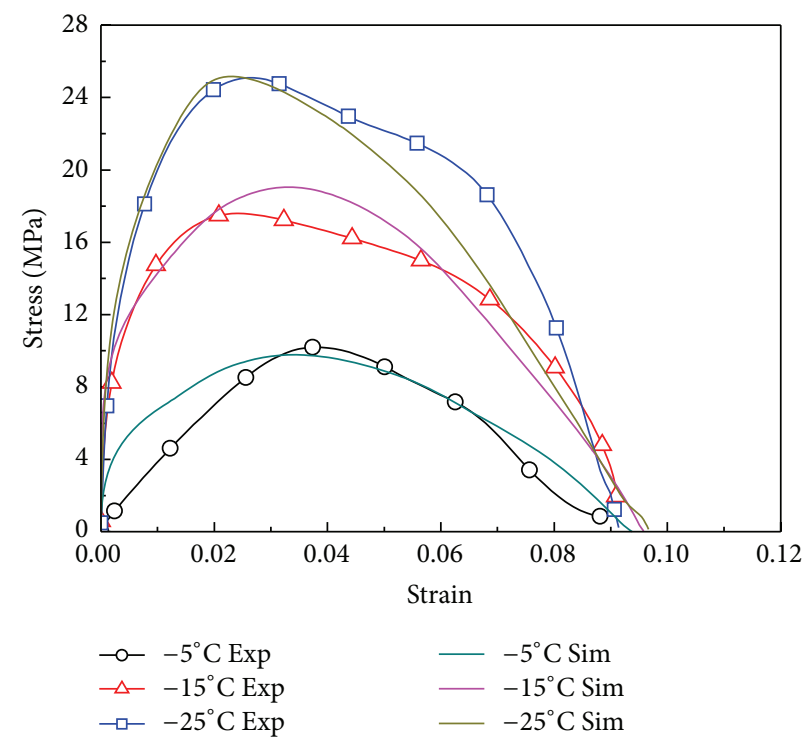

(c) $950 / \mathrm{s}$

FIGURE 15: Comparison of experimental curves and numerical simulation curves under various temperatures.

Figure 14 demonstrates that the peak stress and final strain fit well and increase with increasing strain rate. This result occurs because of the internal structure of frozen soil. The ice in frozen soil is a brittle material, and under the conditions of high-strain-rate impact loading, the damage and destruction of ice crystals play a leading role. At a higher strain rate, more crack extension occurs in the same time, resulting in more energy absorption. Therefore, the stress peak and final strain increase with increasing strain rate, and an apparent strain rate effect is observed.

The second group of experiments were performed at a given impact loading speed (thus, the strain rate is constant), and the experimental temperature was changed.
A comparison of the numerical simulation curves with the experimental curves is shown in Figure 15.

Figure 15 demonstrates that the curves fit well. The peak stress increases with decreasing temperature, and the final strain rate is primarily the same, which is called the strain convergence phenomenon. At a lower temperature, a greater amount of ice remains in the frozen soil; namely, the compressive capacity is higher. Therefore, the temperature effect of frozen soil is apparent.

4.2. Homogeneity Analysis. For the measurement of sample stress uniformity, different studies have adopted different 


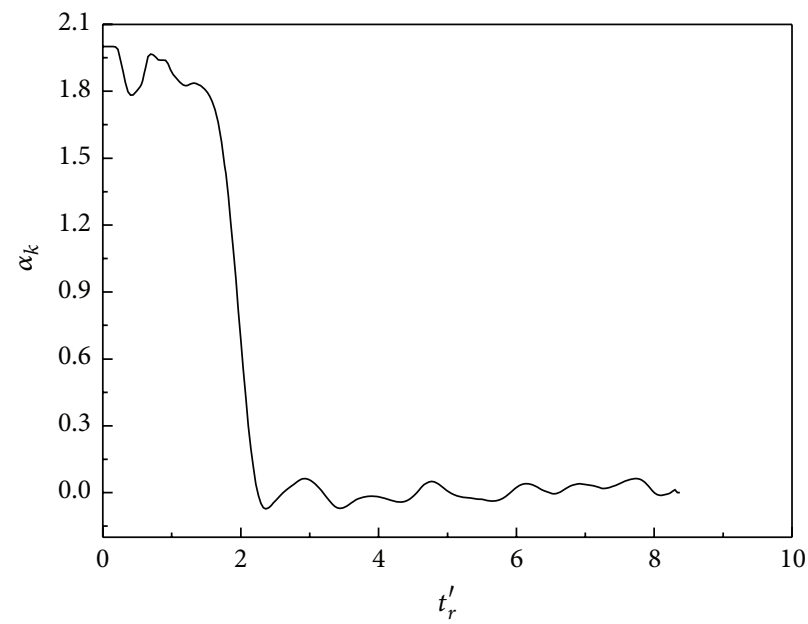

FIGURE 16: Time history-sample stress uniformity curve.

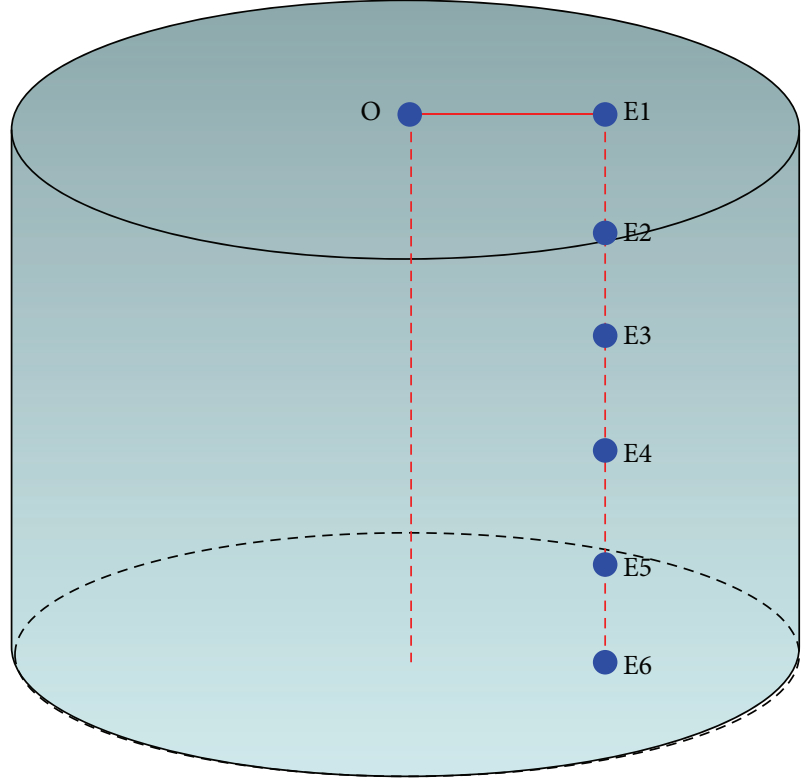

FIGURE 17: Location map of six points within frozen soil.

methods. In this work, the ratio of the stress value difference and the average value on both sides is used to measure the stress uniformity; in terms of $\alpha_{k}$ [17-19], the equation is

$$
\alpha_{k}=\frac{\Delta \sigma_{k}}{\bar{\sigma}_{k}} \times 100 \% \text {, }
$$

where $\Delta \sigma_{k}$ is the stress difference on both sides of the frozen soil, $\bar{\sigma}_{k}$ is the stress average on both sides of the frozen soil, and $\alpha_{k}$ is the ratio between these values. As $\alpha_{k}$ approaches zero, the sample stress uniformity is better. Generally, if $\left|\alpha_{k}\right| \leq$ $5 \%$, the stress distribution in a sample meets the requirement of stress uniformity. In addition, the nondimensional rise time $t_{r}^{\prime}$ is introduced:

$$
t_{r}^{\prime}=\frac{t_{r}}{\tau_{s}},
$$

where $t_{r}$ is the incident wave leading edge rise time and $\tau_{s}$ is the time required for the stress wave to spread from the front

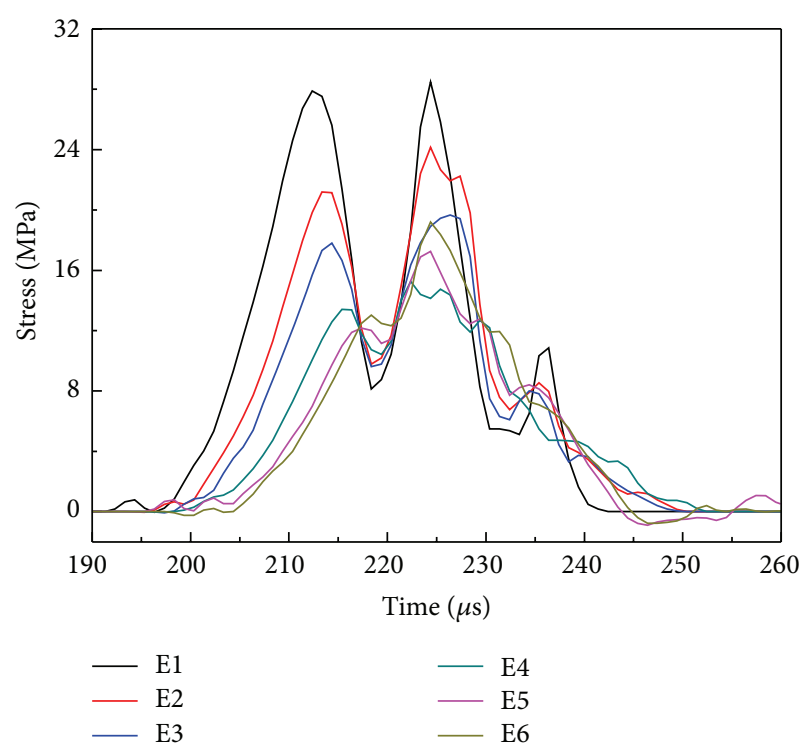

FIGURE 18: Stress-time curves of different points along a vertical shaft of frozen soil.

facet of the sample (close to the incident bar) to the back facet (near the transmission bar) along the loading direction. The relationship between the rise time and stress homogeneity of the sample is shown in Figure 16. The strain rate is 950/s, and the temperature of the frozen soil is $-15^{\circ} \mathrm{C}$.

Figure 16 demonstrates that there is a sharp shock near $t_{r}^{\prime}=1$. Then, the curve quickly approaches zero. For $t_{r}^{\prime} \geq 2$, the shock of the curve decreases. For $t_{r}^{\prime} \geq 3$, the curve is primarily stable, and the overall level is close to zero. The sample is thought to reach a uniform stress state.

4.3. Internal Stress Distribution of Frozen Soil. Along a vertical axis of the frozen soil sample, six points were obtained on average. The vertical wheel base away from the center of the circle was $0.8 \mathrm{~cm}$. The locations of the six points are shown in Figure 17. 


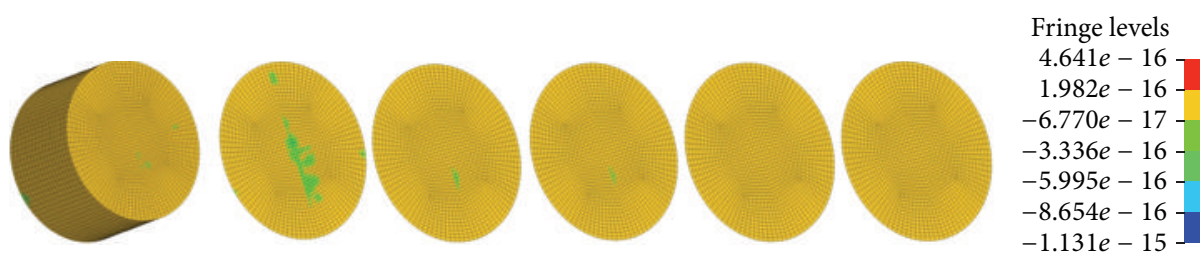

(a) $173 \mu \mathrm{s}$
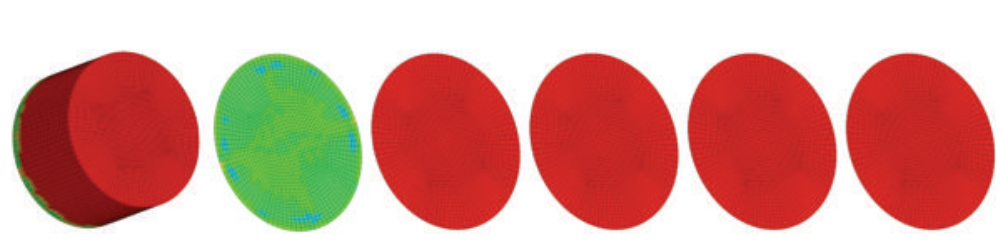

Fringe levels

$-2.097 e-15$

$-5.797 e-08-$

$-1.159 e-07-$

$-1.739 e-07$ -

$-2.319 e-07-$

$-2.898 e-07$

(b) $191 \mu \mathrm{s}$
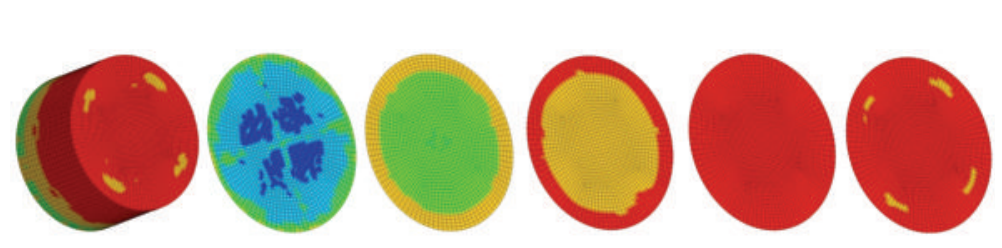

Fringe levels

$3.228 e-06$

$-8.947 e-06-$

$-2.112 e-05-$

$-3.330 e-05-$

$-4.547 e-05-$

$-5.764 e-05-$

$-6.982 e-05$

(c) $201 \mu \mathrm{s}$
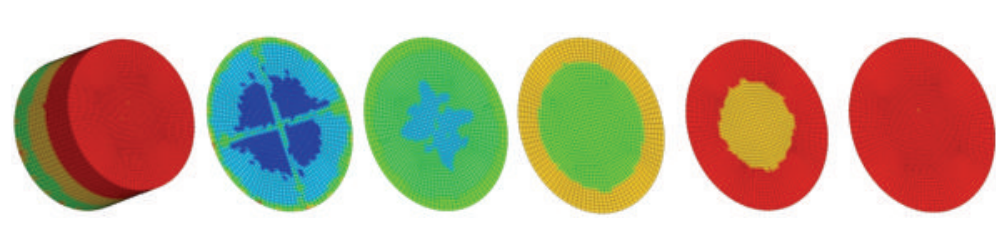

Fringe levels

$-3.420 e-06$

$-5.580 e-05$

$-1.082 e-04-$

$-1.606 e-04-$

$-2.130 e-04-$

$-2.653 e-04$

$-3.177 e-04$

(d) $209 \mu \mathrm{s}$
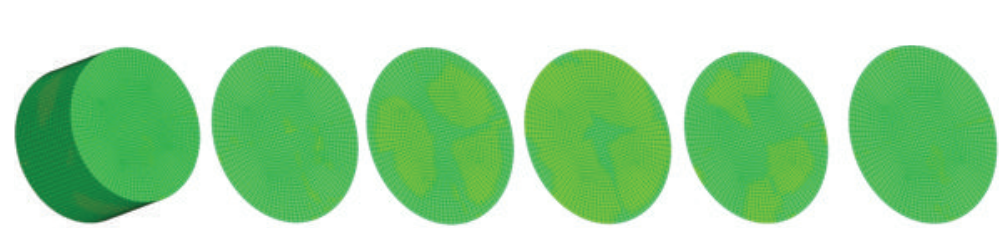

Fringe levels

$-2.504 e-05$

$-6.094 e-05-$

$-9.685 e-05$

$-1.327 e-04$

$-1.687 e-04-$

$-2.046 e-04$

(e) $215 \mu \mathrm{s}$

FIGURE 19: The internal stress distribution clouds of frozen soil.

E1 is a point on the front facet of the frozen soil sample, and E6 is a point on the back facet. The stress-time curves of six points are plotted in Figure 18.

Figure 18 demonstrates that all the curves exhibit a trend that the stress value moves down and up. This result is observed because the stress wave reflects when it is spread to the back facet. The point E1 is forced first at approximately $192 \mu s$, and its oscillation of the first peak is more obvious than the other points because E1 is on the front facet with instability. Then, point E2 is forced at approximately $195 \mu$ s. Finally, E6 is forced at approximately $200 \mu$ s. The propagation from the front facet of the sample to back facet is apparent.

4.4. Impact Failure Mode of Frozen Soil. The failure process of frozen soil in the SHPB experiment is on the level of microseconds level and cannot usually be observed. Even with the use of high-speed camera, only the damage of the outer surface on frozen soil can be roughly observed. The destruction of internal frozen soil cannot be observed. With DYNA numerical simulations, the entire failure process and failure mode of frozen soil can be observed in detail in the form of slices. Based on the numerical simulation results, the failure process can be divided into three stages. The first stage occurs before the failure of the sample; in this stage, uniform stress is achieved through reflection of the shock waves in the sample. The second stage is called the crack formation stage. The third stage is called the crushed sample stage.

The first stage is illustrated in Figure 19. The uniform stress in the sample is achieved before the failure of the sample. To see the internal stress distribution, the sample must be sliced. The stress clouds from left to right are the slices 


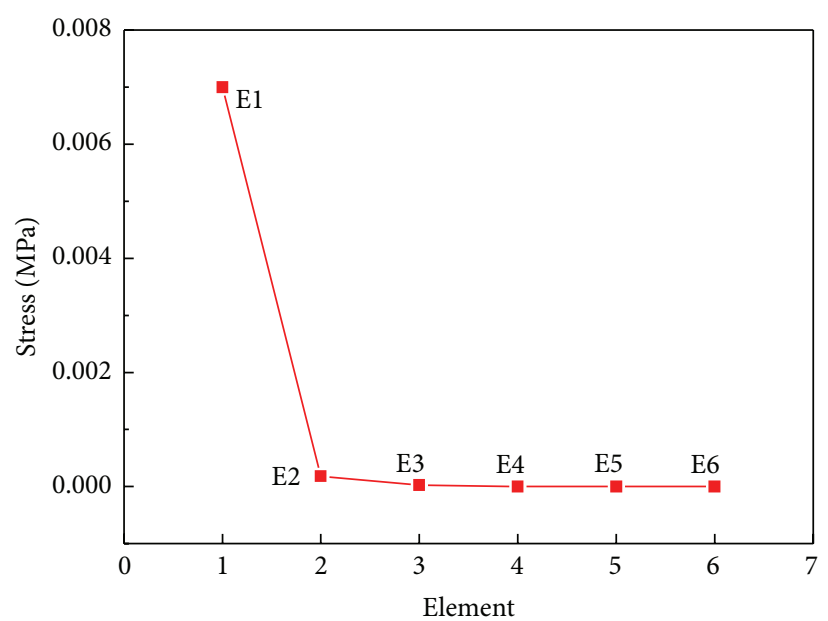

(a) $191 \mu \mathrm{s}$

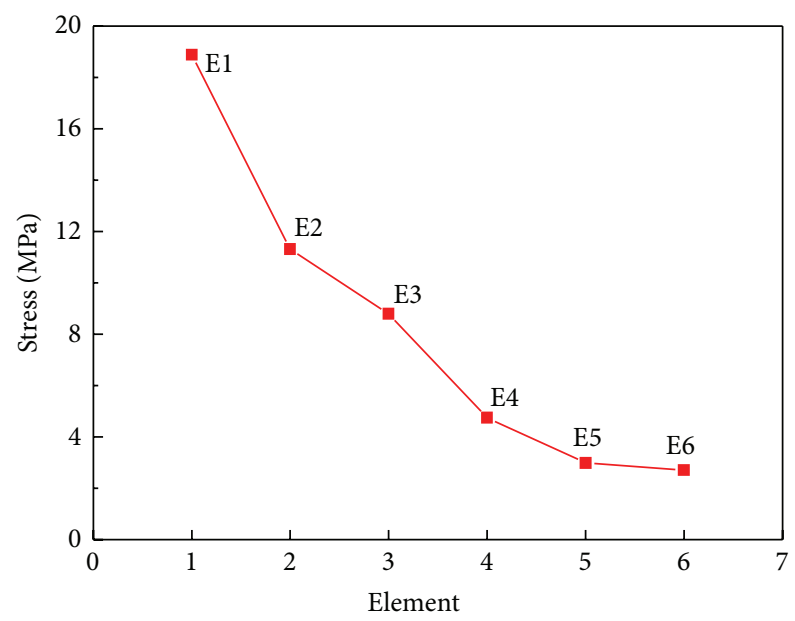

(c) $209 \mu \mathrm{s}$

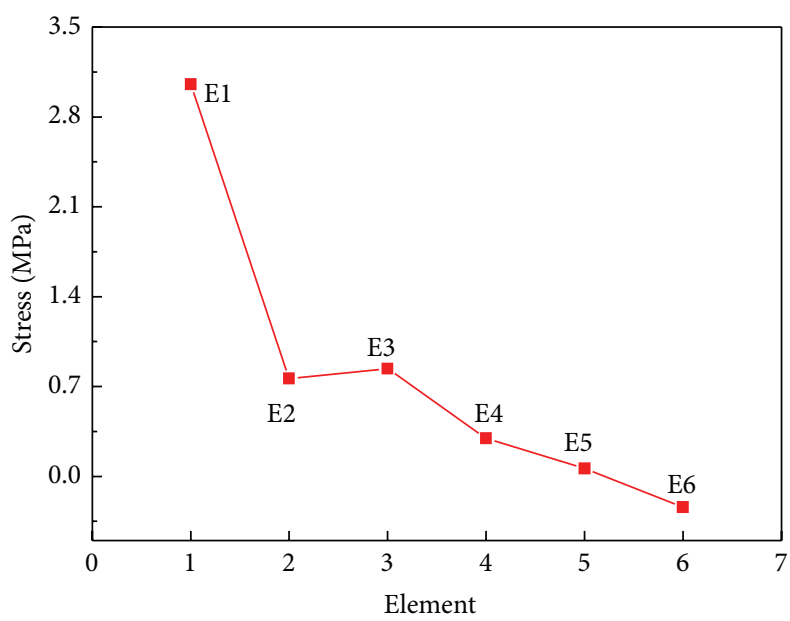

(b) $201 \mu \mathrm{s}$

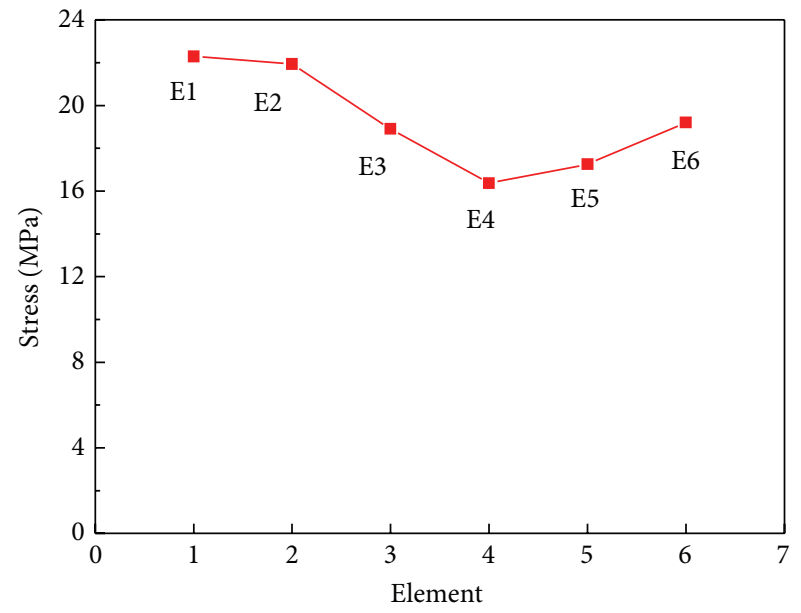

(d) $213 \mu \mathrm{s}$

FIgure 20: Comparison of stress values at different locations.

from the front facet to the back facet of the sample at some moment.

Figure 19(a) shows that the sample is not subjected to force before the shock wave and remains at an equilibrium stress state. In Figure 19(b), the stress wave has just come into contact with the sample, and the front facet of the sample is subjected to the force. Then, the pressure is transferred to the back facet. In Figure 19(c), the stress wave is just reflected on the back facet, and the back facet is under tension. During the process shown in Figures 19(d) and 19(e), the internal stress of the sample is primarily the same, and the sample is thought to achieve a uniform stress state.

To observe the propagation of the stress wave in the sample more clearly and intuitively, six data points were obtained, as shown in Figure 17. E1 is a point on the front facet of the sample, and E6 is a point on the back facet. The stress analyses of the six points are shown in Figure 20.

In Figure 20(a), the front facet has just been subjected to a stress wave, and the stress value of E1 is significantly greater than that at the other points. In Figure 20(b), the stress value of $\mathrm{E} 6$ becomes negative, indicating that the stress wave is reflected and has a tensile function on the back facet. In Figure 20(c), the stress values of the six points exhibit a decreasing trend, indicating the transmission of the stress wave from the front facet to the back facet of the sample. After a period of reflection, the frozen soil sample reaches a uniform stress state, as observed in Figure 20(d).

After the uniform stress is attained in the sample, with the spread of the stress wave, the stress of the sample is gradually increased. Then, the second stage occurs, as observed in Figure 21.

Because of the boundary effect, the forces on the front and back facets of the sample are greater than on the other surfaces. A compression wave forms from the tension wave after it is reflected on the side surface of the sample that is free. Although the tensile strength is not large, because the tensile strength of frozen soil is small, the exterior of the sample would be destroyed first, as illustrated in Figures 21(a) and 21(b). Afterwards, the destruction on the two end faces is extended along the outside and central surfaces. Gradually, the larger pieces shown in Figures 21(c)-21(f) are formed. 


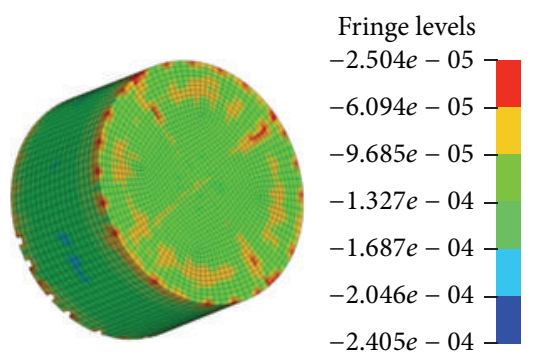

(a) $215 \mu \mathrm{s}$

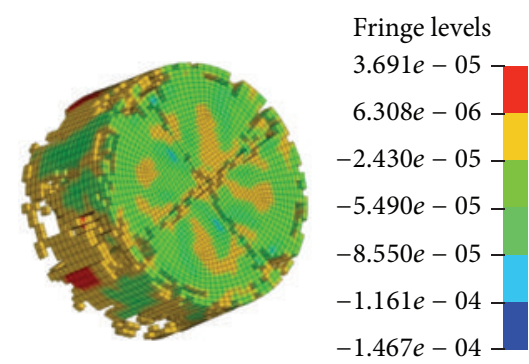

(d) $243 \mu \mathrm{s}$

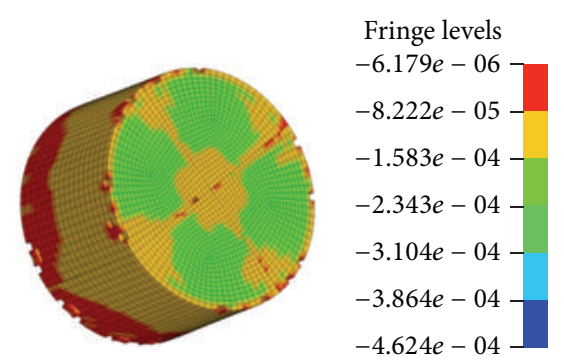

(b) $225 \mu \mathrm{s}$

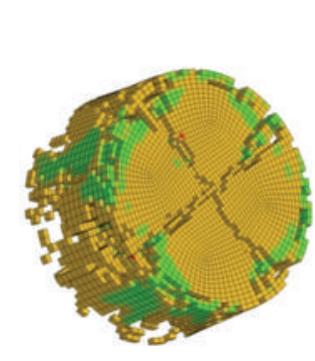

(e) $251 \mu \mathrm{s}$

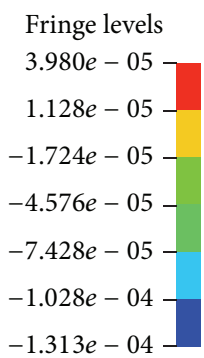

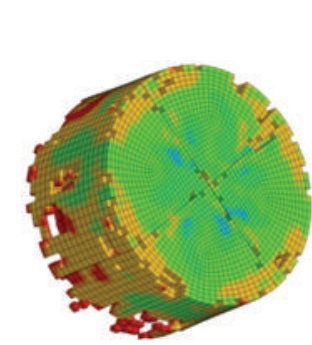

Fringe levels

$3.118 e-05$

$-9.849 e-06$

$-5.088 e-05$

$-9.191 e-05$

$-1.329 e-04$

$-1.740 e-04$

(c) $237 \mu \mathrm{s}$

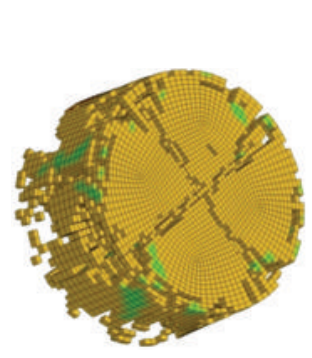

Fringe levels

$4.967 e-05$

$1.042 e-05$

$-2.882 e-05$

$-6.807 e-05$

$-1.073 e-04$

$-1.466 e-04$

$-1.858 e-04$

(f) $255 \mu \mathrm{s}$

FIGURE 21: Stress clouds of damage stage.

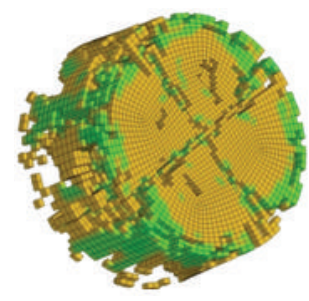

$261 \mu \mathrm{s}$

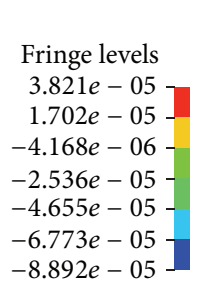

$-8.892 e-05$

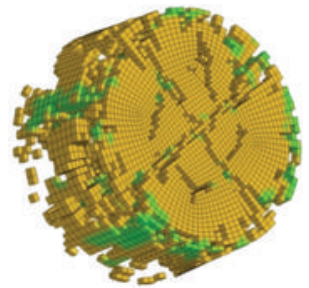

$267 \mu \mathrm{s}$

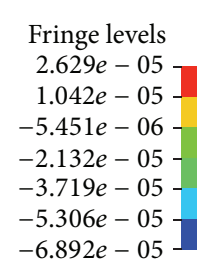

$-6.892 e-05$

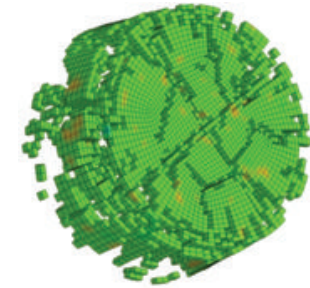

$315 \mu \mathrm{s}$

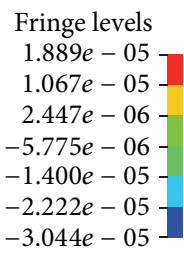

$-3.044 e-05$

FIgURE 22: Stress clouds of crushed sample stage.

If the strain rate is sufficiently high, the sample is destroyed sequentially. The fragments are smaller, and their quantity is greater. This stage is called the third stage (crushed sample stage) and is illustrated in Figure 22.

A higher impact velocity results in a greater loading strain rate and a smaller broken sample. The numerical simulation and experimental results were identical.

\section{Conclusions}

SHPBs with diameters of $30 \mathrm{~mm}$ were used to perform impact experiments of frozen soil under various impact velocities and temperatures. In addition, using the finite element analysis software LS-DYNA, SHPB experiments of frozen soil were simulated.

(1) The strain rate effect and temperature effect of frozen soil under impact loadings were investigated in the experiments. For a given frozen soil temperature, the peak stress and final strain increased with increasing strain rate. For a given strain rate, the peak stress increased with decreasing temperature, and the final strain converged.
(2) Using the HJC model, the dynamic mechanical behavior of frozen soil under impact loadings was numerically simulated. The strain rate effect and temperature effect of frozen soil under impact loadings were verified. In addition, to determine more reasonable parameters for the model, the effects of the sensitive parameters in the HJC model on the calculation results were evaluated.

(3) Using numerical simulations, the stress-strain curves of frozen soil under impact loadings were obtained and compared with the corresponding experimental curves. The curve fitting was good, and the stress uniformity of the frozen soil sample was verified. The stress-time curves of selected points on a vertical axis in sample were obtained. The stress value of each section reached a uniform stress state before its destruction. In addition, the propagation of the stress wave was reflected inside the sample.

(4) Based on the numerical simulation, the destruction process of frozen soil under impact loadings can be divided into three stages: a uniform stress stage, crack formation stage, and crushed sample stage. 
In addition, for a higher impact velocity, the loading strain rate was greater and the broken sample was smaller. The numerical simulation and experimental results were identical.

\section{Competing Interests}

The authors declare that they have no competing interests.

\section{Acknowledgments}

This work was supported by the National Natural Science Foundation of China (11172251) and the Project of Sichuan Provincial Youth Science and Technology Innovation Team, China (2013TD0004).

\section{References}

[1] B. S. Chen, S. S. Hu, Q. Y. Ma, and Z. Y. Tu, "Experimental research of dynamic mechanical behaviors of frozen soil," Chinese Journal of Theoretical and Applied Mechanics, vol. 37, no. 6, pp. 724-728, 2005.

[2] H.-D. Zhang, Z.-W. Zhu, S.-C. Song, G.-Z. Kang, and J.-G. Ning, "Dynamic behavior of frozen soil under uniaxial strain and stress conditions," Applied Mathematics and Mechanics, vol. 34, no. 2, pp. 229-238, 2013.

[3] Q. Y. Ma, J. S. Zhang, W. F. Chen, and P. Yuan, "Analysis of SHPB test and impact compression in confining pressure for artificial frozen soil," Rock and Soil Mechanics, vol. 35, no. 3, pp. 637-640, 2014.

[4] Q. Y. Ma, P. Yuan, W. F. Chen, and J. S. Zhang, "Comparative analysis on dynamic mechanical properties of artificial frozen soil under uniaxial load and confining pressure," Chinese Journal of Underground Space and Engineering, vol. 10, no. 1, pp. 26-29, 2014.

[5] Z.-Q. Liu, J.-K. Liu, B. Wang, H.-L. Zhang, and X.-F. Li, "Dynamic characteristics of frozen clay by using SHPB tests," Chinese Journal of Geotechnical Engineering, vol. 36, no. 3, pp. 409-416, 2014.

[6] Y. Ma, Z.-W. Zhu, W. Ma, and J.-G. Ning, "Characteristics of stress-strain curves and convergence phenomenon of frozen soil under dynamic loading," Engineering Mechanics, vol. 32, no. 10, pp. 52-59, 2015.

[7] M. D. Furnish, "Measuring static and dynamic properties of frozen silty soils," Tech. Rep. 98-1497, Office of Scientific \& Technical Information, 1998.

[8] M. Y. Les, A. Fossum, and S. Laurence, "Frozen soil material testing and constitutive modeling," Sandia Report SAND 20020524, 2002.

[9] X. T. Wu, S. F. Sun, and H. P. Li, "Numerical simulation of SHPB tests for concrete by using HJC model," Explosion and Shock Waves, vol. 29, no. 2, pp. 137-142, 2009.

[10] W. C. Zhu, Y. Bai, X. B. Li, and L. L. Niu, "Numerical simulation on rock failure under combined static and dynamic loading during SHPB tests," International Journal of Impact Engineering, vol. 49, pp. 142-157, 2012.

[11] C. E. Anderson Jr., P. E. O'Donoghue, J. Lankford, and J. D. Walker, "Numerical simulations of SHPB experiments for the dynamic compressive strength and failure of ceramics," International Journal of Fracture, vol. 55, no. 3, pp. 193-208, 1992.
[12] T. Chakraborty, "Impact simulation of rocks under SHPB test," Proceedings of the Indian National Science Academy, vol. 79, no. 4, pp. 605-613, 2013.

[13] T. J. Holmquist, G. R. Johnson, and W. H. Cook, "A computational constitutive model for concrete subjected to large strains, high strain rates, and high pressures," in Proceedings of the 14th International Symposium on Ballistics, vol. 9, pp. 591-600, Quebec, Canada, 1993.

[14] X. Haibin, "The relationship between uniaxial compressive strength of artificial frozen soil and temperature, moisture content," Geotechnical Engineering Word, vol. 11, no. 4, pp. 6063, 2008.

[15] Z. Jingfeng, "An experimental study on the relationship between tensile strength and temperature and water ratio of frozen soil," Geology and Prosprcting, vol. 47, no. 6, pp. 1158-1161, 2011.

[16] L. Wang, Q. Hu, X. Ling, D. Cai, and X. Xu, "Experimental study on dynamic shear modulus of remolded frozen silty clay for Qinghai-Xizang Railway," Journal of Earthquake Engineering and Engineering Vibration, vol. 27, no. 2, pp. 177-180, 2007.

[17] Z. Fenghua, W. Lili, and H. Shisheng, "On the effect of stress nonuniformness in polymer specimen of SHPB tests," Journal of Experimental Mechanics, vol. 7, no. 1, pp. 23-29, 1992.

[18] P. Feng, Q.-M. Zhang, L. Chen, and W. Yao, "Influence of incident pulse of slope on stress uniformity and constant strain rate in SHPB test," Transaction of Beijing Institute of Technology, vol. 30, no. 5, pp. 513-516, 2010.

[19] L. Song and S.-S. Hu, "Stress uniformity and constant strain rate in SHPB test," Explosion and Shock Waves, vol. 25, no. 3, pp. 207216, 2005. 


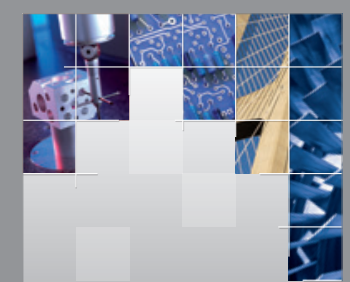

\section{Enfincering}
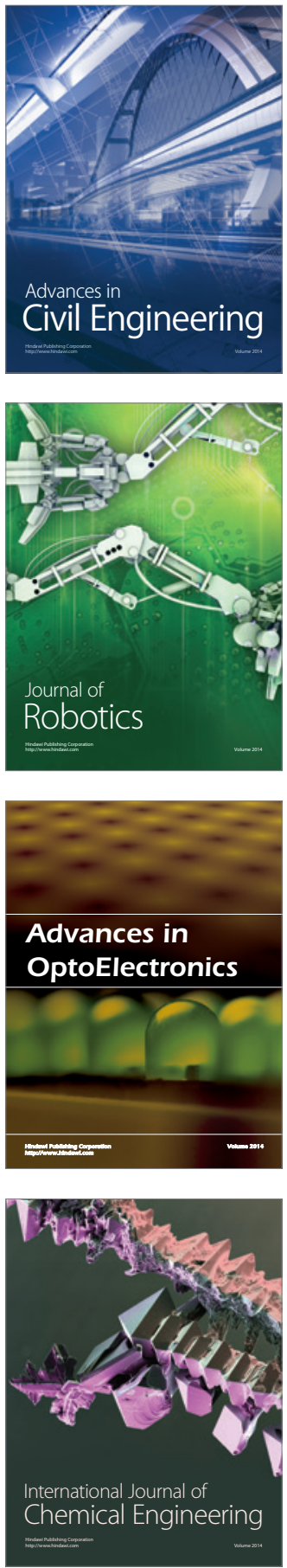

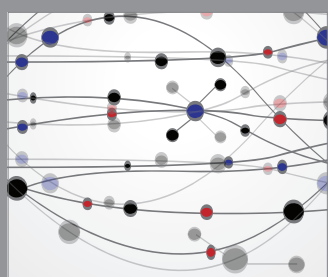

The Scientific World Journal

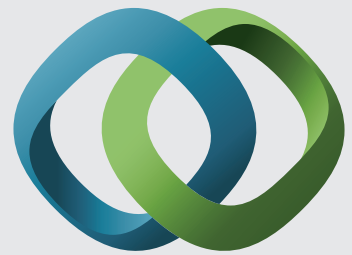

\section{Hindawi}

Submit your manuscripts at

http://www.hindawi.com
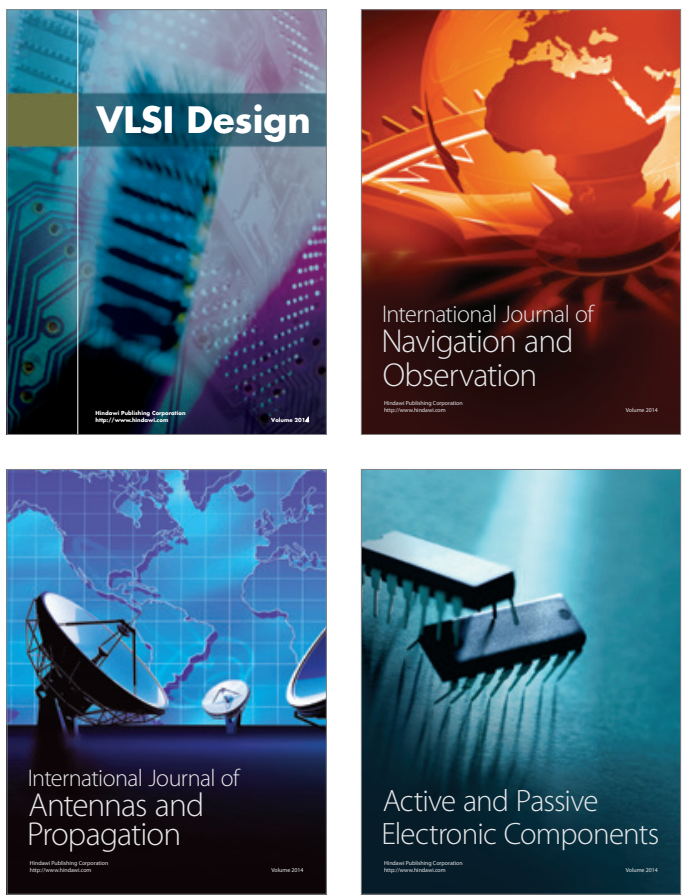
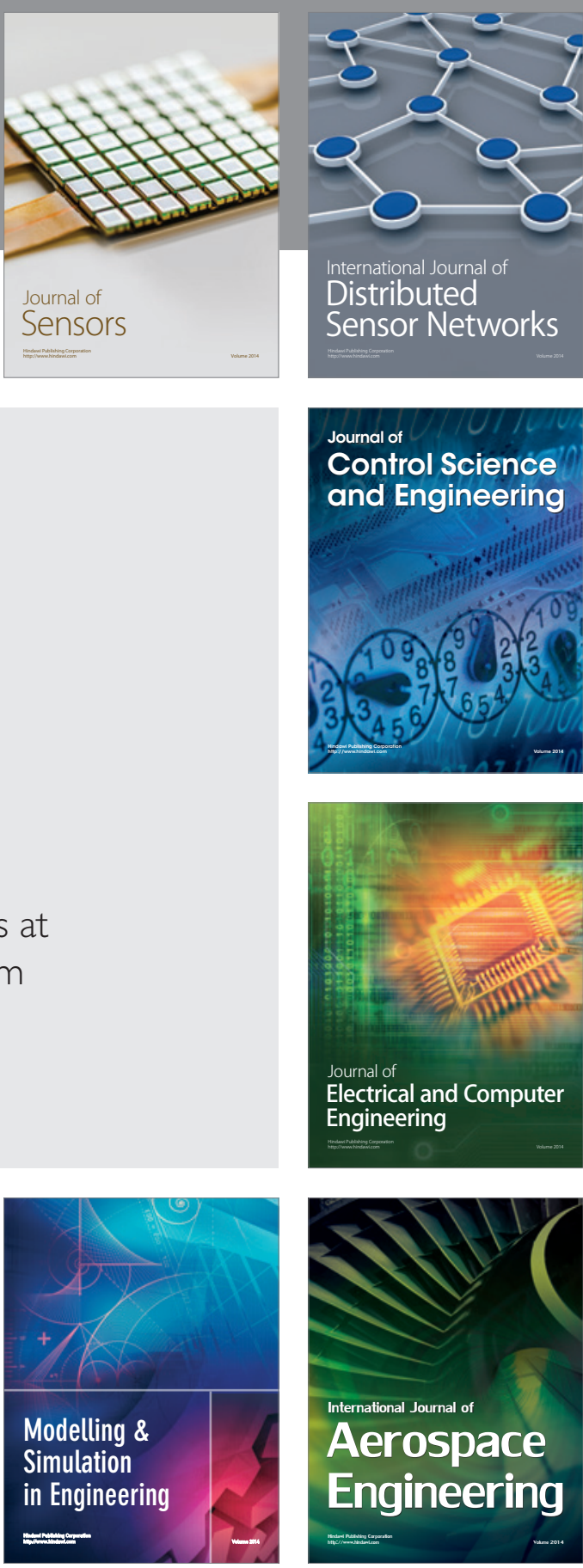

International Journal of

Distributed

Sensor Networks

Journal of

Control Science

and Engineering
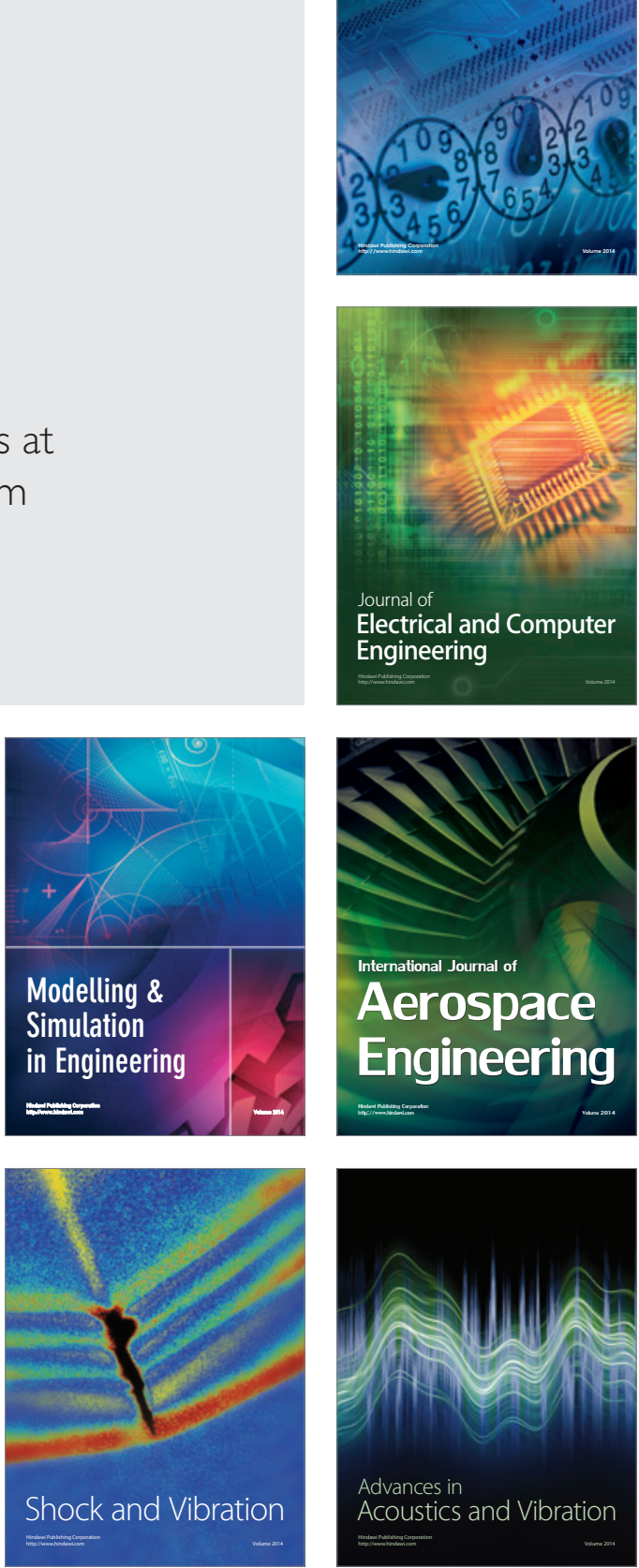